Central Finding: Three-way Interaction among Innovation Orientation, ERC Productivity, and Role Significance Predicting Organizational and Professional Commitment.

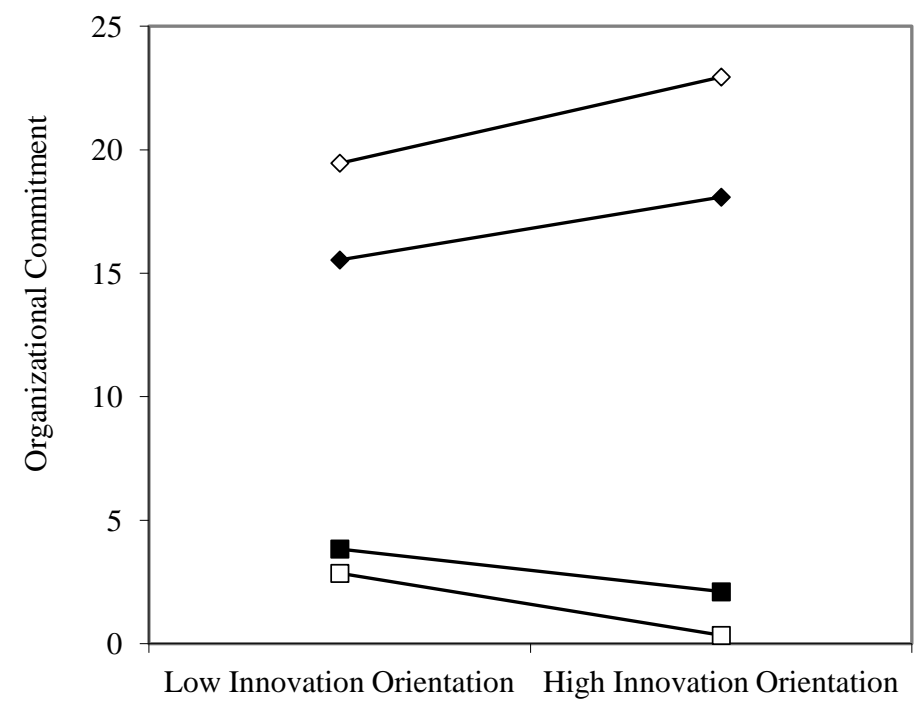

$\checkmark(1)$ High ERC Productivity, High Role Significance

$\neg$ (2) High ERC Productivity, Low Role Significance

$\square-(3)$ Low ERC Productivity, High Role Significance

$\rightarrow$ (4) Low ERC Productivity, Low Role Significance

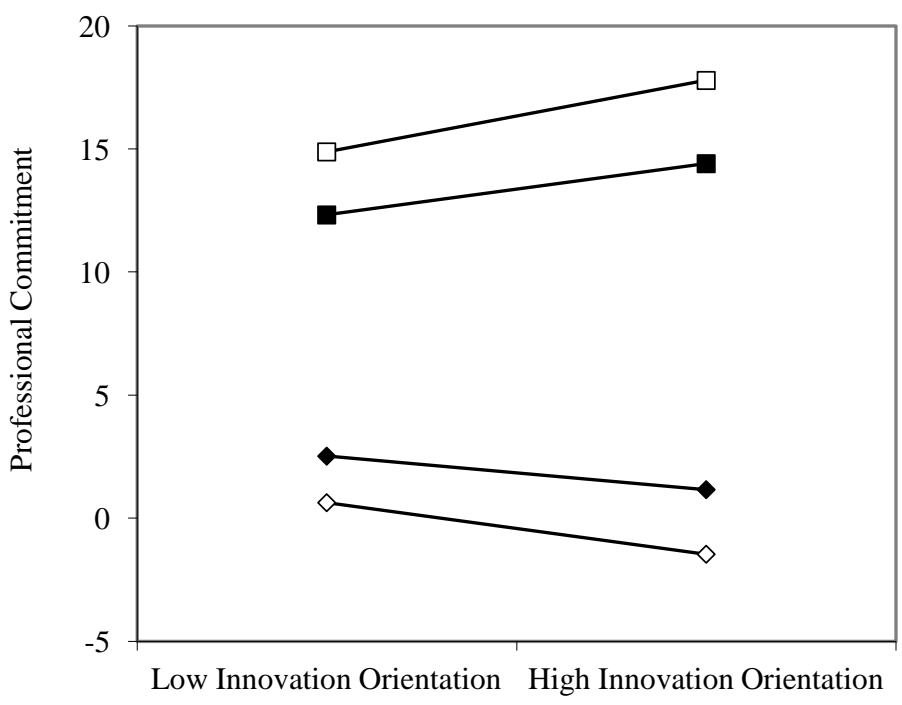

$\checkmark$ (1) High ERC Productivity, High Role Significance

$\longrightarrow$ (2) High ERC Productivity, Low Role Significance

$\neg \square$ (3) Low ERC Productivity, High Role Significance

$\longrightarrow$ (4) Low ERC Productivity, Low Role Significance

Low Innovation Orientation High Innovation Orientation 
Managing the Innovators: Organizational and Professional Commitment

among Scientists and Engineers

\author{
Sara Jansen Perry \\ Baylor University \\ Sara_Perry@baylor.edu \\ Emily M. Hunter \\ Baylor University \\ Emily_M_Hunter@baylor.edu \\ Steven C. Currall \\ Southern Methodist University \\ scc@mail.smu.edu
}

Corresponding author: Sara Jansen Perry, Baylor University, Hankamer School of Business, One Bear Place \#98006, Waco, TX 76798-8006, sara_perry@baylor.edu, 254-710-4623 (office), 832-445-7263 (cell) 


\title{
Managing the Innovators: Organizational and Professional Commitment \\ among Scientists and Engineers
}

\begin{abstract}
How can leaders best manage commitment among innovators? We applied theory on dual allegiance to multiple targets of commitment, in conjunction with person-organization fit theory, to explore the dynamics of organizational and professional commitment among scientists and engineers working in hybrid, research-focused organizations. These types of organizations are founded on large-scale multidisciplinary and multinstitutional collaboration between academe and industry. Using both individual- and organizational-level variables collected from 255 academic science and engineering researchers working in 22 National Science Foundation-funded Engineering Research Centers, our analyses revealed that researcher innovation orientation (i.e., the predisposition to approach work in novel ways) was positively associated with organizational and professional commitment. Those relationships were moderated by two factors: organizational productivity in late-stage technology transfer and the researcher's perceived role significance (i.e., in fulfilling the strategic mission of the organization). The strongest positive relationship between innovation orientation and organizational commitment emerged among researchers who perceived high role significance and worked in highly productive organizations. A negative relationship between innovation orientation and professional commitment also emerged among those individuals. Post-hoc analyses revealed that highly innovative, senior researchers who perceived high role significance were the most likely to report higher levels of both organizational and professional commitment. Leaders of multidisciplinary research centers who are aware of the complexity of dynamics among organizational commitment, professional commitment, and role significance may be better equipped to effectively manage science and engineering researchers.
\end{abstract}

Keywords: Innovation Orientation, Technology Transfer, Organizational Commitment, Professional Commitment, Role Significance, Multi-Institutional Multi-Disciplinary University Research Centers 


\section{Introduction}

Scientists and engineers are deeply involved in the generation of new innovations (Keller, 2012), but despite some promising insights on motivational forces among scientists and engineers (Sauermann \& Cohen, 2010), organizational leaders continue to question how to best manage, motivate, and retain these unique individuals. It is widely believed that scientists and engineers are more committed to their profession than their organization, enjoy relatively high mobility, are more intrinsically than extrinsically motivated, and exhibit highly innovative, sometimes non-conformist tendencies, which may help or harm the organization (Burton \& O'Reilly, 2004; Keller, 1997; 2012; Lam, 2011; Mainemelis, 2010; Morrow \& Wirth, 1989; Schein, 1971). Thus, the motivations of scientists and engineers are complex, and may be difficult to predict by leaders (Lam, 2011). But often, creativity and innovation lie at the root of these complexities, which are highly valued because they predict organizational performance (Keller, 2012; Krauss, Frese, Friedrich, \& Unger, 2005; Lumpkin \& Dess, 1996). Thus, these topics are worthy of further study by management scholars.

Applying a broad stream of literature on organizational and professional commitment to highly innovative research organizations, in conjunction with person-organization fit theory, we posit that the most innovative researchers experience good fit in such organizations, which produces commitment (Kristof-Brown, Zimmerman, \& Johnson, 2005; Solinger, van Olffen, Roe, \& Hofmans, 2013). Despite assumptions to the contrary, organizational and professional commitment may not necessarily be incompatible. We draw from work on dual allegiance to explore the processes that may predict commitment to both referents (Tuma \& Grimes, 1981), thus contributing to "an old debate in a new context." ${ }^{\text {N }}$ Namely, we explore factors that may help leaders enhance both organizational and professional commitment among scientists and engineers who work across organizational and disciplinary boundaries, which may lead to more effective motivation and retention strategies (Guest, 2002; Mathieu \& Zajac, 1990).

${ }^{1}$ We thank an anonymous reviewer for this phrase. 
We also analyze two additional factors - individual role significance and the impact of the organization's research outside the laboratory. These may help leaders nurture loyalty from innovativelyoriented, professionally-focused individuals. Research organizations that are successful in moving research outputs to the public sphere where they can have an impact may offer unique opportunities to academic scientists and engineers, in contrast to their mainstream profession where fewer such opportunities exist (Solinger et al., 2013; Tuma \& Grimes, 1981). Furthermore, when scientists and engineers experience a sense of personal significance in the strategic mission of the organization (i.e., role significance), their fit with the organization and its technology transfer efforts may be even more salient to them (Lam, 2011). We apply Tuma and Grimes' (1981) theoretical work, as well as work on dual allegiance, fit theory, and strategic human resource management (HRM) to better understand these two forms of loyalty.

\subsection{Contributions to the Literature}

In positing and testing our model with a field sample of academic scientists and engineers, we aim to make four contributions to the literature. First, we contribute to literature on dual allegiance, or multiple foci of commitment, thus broadening the field's understanding of levels of commitment to one's profession and organization. We take an interactionist approach and integrate Tuma and Grimes' (1981) work with person-organization fit theory to better understand the relationship between distinct commitment targets. Our results offer theoretical insight into those theories, as well as practical recommendations for leaders who aim to foster loyalty from scientists and engineers. As a second contribution, we explore the role of a stable predisposition, innovation orientation, in the development of commitment. Innovation orientation is a good starting point for better understanding these unique, highlyvalued researchers, where they best fit in, and how loyalty is cultivated. Third, by considering the crosslevel moderation effect of organizational productivity, we aim to contribute to the innovation and technology transfer bodies of literature, building on work in strategic HRM (e.g., Guest, 2002) that explores links between work factors, employee commitment, and organizational productivity. This is in contrast to many studies on technology transfer that only explore predictors of innovation outputs (e.g., 
invention disclosures, patents, or licenses; Becheikh, Landry, \& Amara, 2006; Dietz \& Bozeman, 2005; Hunter, Perry, \& Currall, 2011; Keller 2012). Thus, we aim to shed light on the role of organizational performance influencing the effect of individual differences and work experiences on commitment to one's organization and profession.

Finally, as a fourth contribution, we add to the knowledge base on research organizations. National Science Foundation (NSF) Engineering Research Centers (ERCs), the setting of our study, are one example of an increasingly popular and vital organizational form - multi-institutional, multidisciplinary university research centers (MMURCs). Other similar organizations include the advanced manufacturing centers funded by the United States Congress in 2015, the Intel Collaborative Research Institute, and the Francis Crick Institute in the United Kingdom. MMURCs contribute significantly to the economy, particularly as companies have moved away from doing their own basic research (Author, 2014; Boardman \& Bozeman, 2007; Hunter et al., 2011; Lam, 2007; Perry, Currall, \& Stuart, 2007). This hybrid organizational form is evolving at a faster pace than the management research surrounding it, and case studies indicate that traditional management knowledge cannot always be generalized to this unique organizational context (Corley, Boardman, \& Bozeman, 2006). As these types of organizations become increasingly common, it is imperative to understand how to effectively lead them (Boardman \& Bozeman, 2006; Hunter et al., 2011).

\section{Theoretical Background}

\subsection{The Context}

We begin with a brief overview on the contextual focus of our study, hybrid organizations involved in complex multidisciplinary research, broadly called MMURCs. The characteristics of these organizations may have important implications for the theoretical foundation of our hypotheses. These research centers offer unique opportunities because they are hybrid environments, which contain attributes of both industry and academia (Roach \& Sauermann, 2010). They are typically based in multiple universities in partnership with multiple industry partners and/or government agencies. Although researchers in MMURCs typically work for one of the partner universities, the most proximal "boss" for 
employees is the research center's leadership. In this way, MMURCs are hierarchically positioned much like a traditional department in a traditional university. Likewise, the "employees" of MMURCs are typically first and foremost academic researchers who likely chose an academic career in part because of the research autonomy offered in that career path (Roach \& Sauermann, 2010). Still, the primary mission of an MMURC is to generate significant, relevant, multi-disciplinary research outputs, with a focus on commercialization of those outputs and training of students to do the same. This is not the typical mission of a university, nor is it the emphasis in most academic training programs that focus on publication in academic journals (Dietz \& Bozeman, 2005).

Researchers are typically asked to join an MMURC because they exhibit both a commitment to scientific excellence and some level of willingness to engage in innovation activities, including commercialization of research. Even so, issues of competing loyalties, goals, and incentives may arise as they consider how to achieve "success" in their employing university, their research center, and their profession overall. Particularly when reward structures are not aligned, researchers may be faced with the possibility of dual allegiance, reflected in attitudes of commitment. We focused on two proximal foci of commitment for the scientists and engineers in our sample - the research center (the most proximal "boss" compared to the broader university) and the profession. We assert that the lessons learned in MMURCs can also help leaders in other types of hybrid organizations, particularly those in which knowledge work is forefront.

\subsection{Organizational and Professional Commitment}

Formally defined, organizational commitment is one's "identification with and involvement in" the employing organization, which we defined as the research center (Porter, Steers, Mowday, \& Boulian, 1974, p. 604). We focused on affective commitment, which reflects pride in belonging and emotional attachment to the organization. This form of commitment predicts continued, enthusiastic engagement with and contribution to the MMURC and its technology commercialization efforts, and is thus most critical for managers of scientists and engineers in these types of research centers to understand (Harrison, Newman, \& Roth, 2006; Meyer, Stanley, Herscovitch, \& Topolnytsky, 2002; Porter et al., 1974). The 
other two forms of commitment proposed by Meyer et al. (2002), normative and continuance, were less relevant to our examination because they emphasize loyalty that is not rooted in true liking for the organization. Instead, normatively committed individuals may stay only because it is the right thing to do, whereas continuance commitment implies a feeling of being stuck, with a lack of better options or too much prior investment to leave.

Professional commitment describes an individual's loyalty to a chosen career, colleagues doing similar work, and the professional norms agreed upon by that group of colleagues (Morrow \& Wirth, 1989). Highly educated individuals like scientists and engineers tend to have a strong loyalty toward their profession because they spend considerable time connecting with non-organizational colleagues in pursuing advanced educational degrees, attending professional conferences, and fostering ongoing work collaborations (Dietz \& Bozeman, 2005; Mathieu \& Zajac, 1990; May, Korczynski, \& Frenkel, 2002; Wang \& Armstrong, 2004). This may also be explained by strong intrinsic motivation to the work itself, which the profession represents (Burton \& O'Reilly, 2004; Lam, 2011; Roach \& Sauermann, 2010). Organizational commitment among a highly professionally committed workforce like scientists and engineers is thought to be generally lower, albeit less understood (Wang \& Armstrong, 2004).

Much debate has occurred about the idea of dual allegiance, or competing loyalties to more than one referent. Dual allegiance is not a new concept (with research dating back to Kornhauser, 1965), but remains understudied in the commitment literature. Kinnie and Swart (2012) highlighted the lack of literature on external commitment targets, in particular the profession and external clients. They explored commitment among knowledge workers, suggesting that the perceived "boss" may vary for each person, depending on priorities and values, and influence resulting levels of commitment. Although this naturally implies competing loyalties, they and other scholars emphasize that commitment may "spill-over and magnify commitment" in multiple domains, particularly when domains are compatible (Parks, Kidder, \& Gallagher, 1998, p. 718). Meta-analytic research supports this notion, revealing a positive association between organizational and professional commitment (Meyer et al., 2002; Wallace, 1993; Wang \& Armstrong, 2004). 
Indeed, organizations stand to benefit from both types of commitment, although organizational commitment is most actionable to leaders of research scientists and engineers. An employee's desire to be well-connected and well-positioned within their profession (professional commitment) can translate to organizational access to high-potential employees, visibility to the industry, improved knowledge transfer, and professional development opportunities for employees (Blau, Surges Tatum, \& Ward-Cook, 2003; Liebeskind, Oliver, Zucker, \& Brewer, 1996). Thus, it behooves scholars to explore how both develop as potential dual allegiances.

To help shed light on the possibility of dual allegiance to the organization and profession, we apply Tuma and Grimes' (1981) framework of commitment. It suggests that individuals may be highly committed to multiple targets of commitment, depending on three boundary conditions: cognitive congruence, organizational selection, and behavioral feedback. First, if goals and values of the organization are congruent with those of the profession, then commitment to both targets can be high. For example, values and goals are consistent when both the organization and profession emphasize and support continuing education in advanced research methods, thus supporting employee participation in such efforts. Second, if organizations select new employees based on both organizationally- and professionally-important characteristics, such as the level of methodological expertise, then commitment to both targets may be high. Otherwise, commitment to the target that best supports the goals and values of the individual is likely to dominate. Third, unique opportunities for success provide positive behavioral feedback, and the individual is likely to increase commitment in the domains providing those opportunities. For instance, if an employee's professional organizations (e.g., the Academy) provide training workshops for research methods but their employing organization will not pay for such training, then a methods-savvy scientist may naturally gravitate toward the profession that provides such opportunities, and away from the organization that does not support their interests.

Our primary objective in this study was to help leaders of scientists and engineers foster organizational and professional commitment among their workforce. In line with Meyer and Allen (1997), we focused on three categories of antecedents to commitment - individual characteristics (i.e., 
innovation orientation), organizational factors (i.e., ERC productivity), and work experiences (i.e., role significance).

\subsection{Individual Innovation Orientation}

Innovativeness is the "willingness to discard old beliefs and explore new alternatives" (Lumpkin \& Dess, 1996, p. 143). Highly innovative individuals are typically higher performers and are rated as more creative and proactive by their supervisors than their less innovatively-oriented peers (Keller, 2012; Krauss et al., 2005; Lumpkin \& Dess, 1996). Scientists and engineers are thought to be highly innovative by nature of their career choice and are often judged by their capacity to innovate (Schein, 1971). We focused on the construct of individual innovation orientation, which is the tendency to approach work in novel ways, use creative work methods, and to prefer non-routine, ambiguous situations where such creative approaches pay off (Robinson, Stimpson, Huefner, \& Hunter, 1991). Measured and conceptualized like a personality trait, it is a stable predisposition to act consistently in certain ways, influencing other aspects of work life, attitudes, and behaviors (Motowidlo, Borman, \& Schmit, 1997). Thus, innovation orientation fits well under Meyer and Allen's (1997) “individual” category of commitment antecedents.

MMURCs offer unparalleled opportunities for innovation in the form of large-scale, interdisciplinary, cutting-edge research that is oriented toward technology transfer (Perry et al., 2007), providing a high level of person-organization fit for individuals high in innovation orientation (KristofBrown et al., 2005). This is in contrast to traditional academic settings, whose reward systems emphasize single-discipline, top-tier publications over practical application (Dietz \& Bozeman, 2005). MMURCs also contrast with private-sector companies whose research and development functions tend to be more incremental and offer less researcher autonomy (Roach \& Sauermann, 2010). Thus, MMURCs are ideal organizations for innovators because those individuals are inclined to go outside traditionally-defined boundaries to solve larger, more complex problems (Schein, 1971). As a hybrid organization, an MMURC provides the bridge between academia and industry, allowing highly innovative researchers to satisfy their "taste for science" in an organization that may feature the best of both worlds, but which does 
not fit neatly into either (Roach \& Sauermann, 2010, p. 422). Thus, MMURCs are likely to attract researchers who are interested in autonomy and high-impact research, but also commercialization of that research. Person-organization fit theory suggests that individuals who experience compatibility with their organization's values experience higher job satisfaction, identification, and commitment (Kristof-Brown et al., 2005; Solinger et al., 2013). Tuma and Grimes (1981) describe this type of fit as cognitive congruence, which is fostered by organizational selection methods emphasizing innovatively-oriented characteristics. Thus, we predicted a positive relationship between innovation orientation and organizational commitment to an MMURC.

Individuals who are high in innovation orientation may also experience fit with their science and engineering profession as they place a high priority on belonging to a profession that supports innovative, creative work. Indeed, science and engineering professions tend to attract innovative scholars, emphasizing life-long learning and high levels of autonomy to explore a wide range of creative pursuits (Schein, 1971; Wang \& Armstrong, 1994). Representatives of the profession also select individuals they believe will succeed and fit with their field as they choose new doctoral student candidates, and coach those students through to academic careers. Thus, Tuma and Grimes' (1981) cognitive congruence and selection mechanisms for commitment (along with person-organization fit theory) would also suggest that highly innovative individuals are likely to be loyal to their science and engineering profession because of compatibility in goals, values, and priorities (Kinnie \& Swart, 2012; Kristof-Brown et al., 2005; Tuma \& Grimes, 1981).

Hypothesis 1. Innovation orientation among scientists and engineers is positively associated with organizational commitment to an MMURC.

Hypothesis 2. Innovation orientation among scientists and engineers is positively associated with professional commitment to their respective science and engineering professions.

\subsection{Organizational Productivity as a Moderator}

As decades of interactionist research and seminal theory on commitment suggest, loyalty to an organization and profession likely also depends on organizational factors (Chang \& Choi, 2007; Meyer \& 
Allen, 1997). Indeed, some organizations and professions may foster a more attractive environment than others, which impacts loyalty. We apply Tuma and Grimes' (1981) third mechanism, behavioral feedback, in conjunction with fit theory, to suggest that an MMURC's productivity in technology transfer may influence the relationships specified in Hypotheses 1 and 2.

In this study, productivity reflects the extent to which an MMURC makes an impact outside the research laboratory through successful technology transfer (i.e., commercialization). Despite its minimal weight in most academic rank and tenure decisions (Dietz \& Bozeman, 2005), technology transfer is a vitally important pursuit and central to the mission of MMURCs. New technology innovations often make a significant impact on the economy, visibility of universities, and national scientific rankings, not to mention the overall quality of human life (Choi \& Chang, 2009; Miller, Fern, \& Cardinal, 2007; Smilor, Dietrich, \& Gibson, 1993). In operationalizing productivity, we focused on later-stage outputs representing application of research discoveries, including licenses, industry standards, and jobs created within new start-up companies. Although the commercialization pipeline includes many other outputs (e.g., inventions disclosures and patents), later-stage, application-oriented outputs are among the most meaningful ways that these research centers tangibly impact society. Scientists and engineers are likely aware of those organizational impacts even if not personally involved.

Employees who work in an organization that offers opportunities to make a meaningful impact, particularly in ways that the mainstream profession does not offer, may experience positive behavioral feedback (i.e., intrinsic rewards; Hackman \& Oldham, 1976; Lam, 2011; Schein, 1971; Tuma \& Grimes, 1981). This positive feedback may alter the previously specified associations between innovation orientation and both forms of commitment by highlighting differences between the MMURC and the mainstream profession, perhaps highlighting higher levels of fit with one domain. For example, innovatively-oriented individuals may exhibit even stronger commitment to an MMURC than they otherwise would when it offers significantly more unique and exciting opportunities in the form of commercialization, thereby fulfilling their expectations of compatible values toward innovation (Harrison et al., 2006; Sturges, Conway, Guest, \& Liefooghe, 2005; Tuma \& Grimes, 1981). At the same time, the 
goals of the mainstream science and engineering profession may seem less compatible, if it does not offer the same unique activities as the MMURC, thus warranting less loyalty than an innovatively-oriented individual might otherwise engender. In other words, when loyalty to the MMURC is reinforced through positive behavioral feedback, loyalty toward the mainstream profession may wane. Thus, when organizational productivity is higher, we expect a positive innovation orientation-organizational commitment relationship and a negative innovation orientation-professional commitment relationship.

In contrast, an MMURC with lower productivity in late-stage technology transfer offers fewer unique opportunities than more successful organizations, thus failing to meet expectations of innovatively-oriented researchers who work there (Harrison et al., 2006; Roach \& Sauermann, 2010; Schein, 1971; Turnley \& Feldman, 2000). This is negative behavioral feedback, and is particularly salient for organizations whose very existence is oriented toward producing high-impact technology transfer (Mainemelis, 2010). Thus, for MMURCs with lower productivity, we expect innovatively-oriented individuals to have lower levels of organizational commitment. In contrast, these same individuals likely focus on their science and engineering professions, and other opportunities they may offer, when success is not achieved in their MMURC. This suggests a positive innovation orientation-professional commitment relationship among individuals in less productive organizations.

Hypothesis 3. Organizational productivity moderates the innovation orientation-organizational commitment relationship, such that the relationship is positive in more productive MMURCs and negative in less productive MMURCs.

Hypothesis 4. Organizational productivity moderates the innovation orientation-professional commitment relationship, such that the relationship is negative in more productive MMURCs and positive in less productive MMURCs.

\subsection{Role Significance as a Work Experience Moderator}

Turning to the third category of antecedents described by Meyer and Allen (1997), work experiences, the above relationships may also depend on the extent to which a researcher is aware of his/her role in the MMURC's overall success (i.e., role significance; Noble \& Mokwa, 1999). We 
specifically define role significance in this context as a person's awareness regarding the importance of their responsibility in the organization's strategic plan implementation effort. Strategic planning was a significant initiative in the organizations we studied, and implementation of the plan by scientists and engineers included knowing where one's research fits into overarching research goals and pursuing research that supports those goals. Thus, this construct nicely captures the work experiences an individual may have in contributing to their organization and their broader profession.

Research in organizational psychology and strategic HRM suggests leaders can increase commitment by clarifying employee roles within the organization, including emphasizing their significance to the overall organization and its strategic efforts (Abramis, 1994; Bray \& Brawley, 2002; Guest, 2002; Hackman \& Oldham, 1976; Lang, Thomas, Bliese, \& Adler, 2007). Role significance can also improve intrinsic motivation, performance, and self-confidence in one's work (Bray \& Brawley, 2002; Hackman \& Oldham, 1976; Noble \& Mokwa, 1999; Saks, Uggerslev, \& Fassina, 2007; Thorpe \& Morgan, 2007), which leads to increased commitment and other favorable attitudes toward the organization (Fried \& Ferris, 1987; Panaccio \& Vandenberghe, 2011; Tubre \& Collins, 2000). A positive experience within the organization may "spill-over to magnify" professional commitment as well, as a researcher feels they have personally made an impact in their field by contributing significantly to the worthy mission of their MMURC (Parks et al., 1998, p. 718). Below we describe the expected form of the three-way interaction with role significance, organizational productivity, and innovation orientation.

\subsubsection{Proposed Three-Way Interaction}

Together, organizational productivity and role significance represent ways that individuals may receive behavioral feedback, in the form of organizational factors and personal work experiences, respectively (Meyer \& Allen, 1997; Tuma \& Grimes, 1981). Role significance may engender feelings of being well-informed, truly needed, valued, and well-positioned for success at work, which may act as behavioral feedback and strengthen the fit an innovative researcher experiences with the organization (Hackman \& Oldham, 1976; Tuma \& Grimes, 1981). When MMURCs offer high levels of behavioral feedback via impactful, extrinsically and intrinsically rewarding endeavors (productivity in technology 
transfer; Lam, 2011), we posit that higher role significance will primarily serve to strengthen those effects.

Those with higher role significance are more aware of their central role in the strategic initiatives of the organization than those with lower role significance (Miller \& Cardinal, 1994; Turnley \& Feldman, 2000). As described above, behavioral feedback from working in a successful, high-impact organization may take the form of intrinsic rewards and unique career opportunities, which innovatively-oriented researchers likely value (Burton \& O’Reilly, 2004; Perry et al., 2007). Individuals reporting high role significance are more aware of their contribution to their MMURC's success, and thus may be more highly committed to their organization than those with lower role significance. In contrast, individuals working in less productive MMURCs experience negative behavioral feedback, perhaps highlighting a lack of fit or unmet expectations in the organization. When individuals are highly aware of their own role significance in a less successful MMURC, they may exhibit even stronger negative innovation orientation-organizational commitment relationships than those with lower role significance, due largely to the increased salience of less organizational success (i.e., unmet expectations, or misfit in values and activities in the organization).

In regard to the profession, as posited above, individuals may focus more on their mainstream profession when the organization is not as successful. Although research on dual allegiance supports the possibility of high levels of both organizational and professional commitment (Kinnie \& Swart, 2012; Parks et al., 1998), the behavioral feedback from an MMURC's successful versus unsuccessful technology transfer may serve to highlight the unique opportunities and cognitive congruence with the MMURC versus the profession (Tuma \& Grimes, 1981). Thus, we expected the relationships specified in Hypotheses 5 and 6 to be stronger among those reporting high role significance.

Hypothesis 5. Organizational productivity and role significance jointly moderate the effect of innovation orientation on organizational commitment, such that the relationship is positive when productivity is high and negative when productivity is low. The relationships will be strongest when role significance is high. 
Hypothesis 6. Organizational productivity and role significance jointly moderate the effect of innovation orientation on professional commitment, such that the relationship is negative when productivity is high and positive when productivity is low. The relationships will be strongest when role significance is high.

\section{Methods}

\subsection{Participants and Procedure}

Our sample consisted of academic scientists and engineers involved in research at active ERCs across the United States (see also Author, 2014). ERCs are one specific type of the broader hybrid organization, MMURCs, to which we have referred thus far. As official NSF-funded entities, ERCs go through a rigorous grant proposal process. They receive 10 years of funding from NSF, during which they engage in strategic planning for research endeavors, file annual performance reports with the NSF, and are closely monitored through site visits. At the time of our study, 22 ERCs were actively receiving NSF funding at varying points during their 10-year lifespan. Before designing our study, we conducted semistructured, in-person or phone interviews with at least one representative from every active ERC and the NSF overseers of the ERC Program. We visited 11 ERCs in person to interview people across all roles, and we also attended an annual conference for the ERC Program. This pre-study preparation was undertaken in order to fully understand the ERC context before collecting survey data.

We sent invitation emails to approximately 800 scientists and engineers working at the 22 ERCs to participate in an online survey. The directors of the ERCs also sent emails drafted by the research team to encourage participation. In total, 255 scientists and engineers completed the survey (31\% response rate; on average, 11.6 persons per ERC, ranging from 3 to 25). All were employed by a university involved in the ERC, thus making all respondents subject to the academic compensation and incentive structure, with some minor variances depending on official title and role. Consistent with the demographic makeup of ERCs, $80 \%$ were male and $73 \%$ were Caucasian (4\% were of African descent, $14 \%$ were Asian, $6 \%$ were Hispanic, and 3\% were 'Other'). We only included individuals involved in research, which included postdoctoral positions (4\%), assistant (17\%), associate (26\%), full (42\%), and emeritus (1\%) professors, and 
research scientists in non-faculty positions (10\%). Of those, 63\% held a leadership role in the ERC (ranging from project leader to director of the ERC).

\subsection{Measures}

3.2.1 Commitment. We assessed affective organizational commitment using the 9-item short form of the Organizational Commitment Questionnaire (OCQ) from Porter, Steers, Mowday, and Boulian (1974). Sample items are "I find that my values and the ERC's are very similar" and "I really care about the fate of this ERC." Participants used a 7-point agreement scale (7 = "Strongly Agree"). We chose this measure because it is highly correlated with the more popular affective commitment scale (Allen \& Meyer, 1996), but the item wording was more compatible with our sample and context (e.g., "I really care about the fate of this ERC" rather than Allen and Meyer's (1996) language of being "emotional attached" and "part of the family"). We assessed professional commitment using Wang and Armstrong's (2004) 7item measure. Respondents were asked how important each item was to them (7="Very Important"; e.g., "Belong to a professional community of others in my field" and "Earn excellence in the eyes of colleagues outside my ERC"). Based on modest reliability, we dropped two items from the organizational commitment scale ("I am willing to put in a great deal of effort beyond that normally expected in order to help this ERC be successful" and "I would accept almost any type of job assignment in order to keep working with this ERC”) and one item from the professional commitment scale ("Have adequate career prospects within my chosen profession"). The fit of each of the measurement models for these revised scales, and the full measurement model for all constructs using these revised scales, were acceptable (see Appendix A; Hu \& Bentler, 1999).

3.2.2 Innovation orientation. We measured innovation orientation using five items from the innovation behavior subscale of Robinson et al.'s (1991) Entrepreneurial Attitude Orientation (EAO) questionnaire ( 7 = "Strongly Agree"). We chose this scale because it assessed the overall inclination of scientists and engineers to behave in specific innovative ways, which may deviate from established norms, but which were also highly relevant to the ERC context. We chose a measurement strategy consistent with widely-accepted personality assessment methods, which consider individual differences as 
reflecting consistent patterns of behaviors exhibited, rather than less-stable behaviors exhibited in response to a stimulus or during a narrow time period (Goldberg et al., 2006; Hogan, 2005). By definition, personality, or more generally, an individual predisposition, describes one's "fundamental capacities and ... abstractions that define potential for observable behavior" (Motowidlo et al., 1997, p. 78). Thus, we used behaviorally-focused items consistent with well-established personality assessments (e.g., Conscientiousness from the Big Five Framework is measured by items such as "I get chores done right away"). Also in line with personality assessment methods, we instructed respondents to indicate how much they agree with each statement in terms of how they typically behave, rather than to rate the frequency with which they have exhibited an episodic behavior in the recent past. Thus, we assert that this scale captured a stable orientation (i.e., behavioral pattern) toward innovation, which is best positioned as an ex-ante predictor (i.e., how innovatively oriented a person generally is) rather than as an ex-post behavior (i.e., how innovatively someone has behaved in a narrow timeframe or in response to a stimulus). An exploratory factor analysis revealed two clear factors of the scale's original nine items innovation orientation and non-conformist orientation (e.g., "I always follow accepted practices in the dealings I have with others" [reversed]). Innovation orientation focused on the creative ways in which individuals do their work (e.g., "I often approach tasks in unique ways"), and was consistent with our theoretical interest, so we retained only those five items.

3.2.3 Role significance. We measured each individual's perceived significance in implementing the strategic plan using two context-specific items based on the role clarity scale from Rizzo, House, and Lirtzman (1970): "I am aware of my role in achieving the ERC's strategic plan" and "I am aware of my thrust(s)' role in achieving the ERC's strategic plan" (7 = "Strongly Agree"). We included individual and thrust (i.e., research team) as distinct referents because each individual in an ERC was a member of a research thrust that pursued projects within the same broad research area. Our interviews of participants during survey development revealed that most people felt an identification with their research thrust. They also were aware of the other projects pursued in their thrust, which could have been more or less central to the ERC's strategic plan than their own work. We cross-validated this measure with a separate 
sample of ERC members $(\mathrm{N}=65$, including only members of ERCs that were not active at the time of our original data collection). This measure was related in the expected directions to several existing validated measures of similar constructs (role significance, task significance, and role clarity; further details on the validation sample can be obtained from the corresponding author).

3.2.4 Organizational (ERC) productivity. We used archival (i.e., non-perceptual) annual reports for two years prior to the survey to assess recent organizational productivity in late-stage technology transfer. The outputs included were licenses issued, building codes impacted (e.g., earthquake-resistant specifications), technical standards impacted (e.g., new computer languages), new medical standards (e.g., protocols for conducting surgery), and employees in spinoff companies (i.e., jobs created). These were not significantly correlated with each other, indicating they function independently and may be used together to represent an overall picture of productivity. Thus, we summed all instances of these outputs for a total score of ERC productivity. This is an inclusive list of later-stage outputs reported in annual reports to the NSF, which make an impact on the public outside the research laboratory. These also represent actual use of research discoveries, which may be more meaningful than counting invention disclosures or patent applications that may not advance any further (Conti, Gambardella, \& Mariani, 2014). We included all of these because some ERCs were heavily involved in intangible rather than tangible outputs (e.g., four ERCs were funded specifically for advancing earthquake safety, which included development of new building codes). If we had only included typical metrics of technology transfer (e.g., licenses), then those ERCs would have appeared as unsuccessful, even when they achieved their strategic goals by producing important industry-specific standards. Fichman (2001) suggested that this aggregation approach is appropriate and allows for more predictive validity and generalizability when the interest is general innovativeness, rather than understanding effects of specific, individual forms of technology transfer. We obtained the archival data from the NSF directly, which collected annual reports from ERC administrative staff. The NSF did not differentially weight these outputs, but instead considered them in conjunction with all other metrics they monitored to determine the overall progress of 
an ERC toward their stated strategic goals. We chose a two-year timeframe to better capture recent overall productivity, since some years were significantly more productive than others.

3.2.5 Controls. Following Becker's (2005) recommendations, we controlled for three variables that may also influence our outcomes. First, we controlled for ERC age at the time of the survey (in years since NSF funding began), because ERCs were in varying stages of their development within the 10 years of NSF funding, and we expected this may affect both commitment and productivity dynamics. At the individual level, we controlled for gender $(0=$ female, $1=$ male $)$ and leadership role $(0=$ not an ERC leader, 1 = leader). Gender is interesting because fewer females tend to self-select into science and engineering fields (Beede et al., 2011) and thus, it may influence commitment profiles of men versus women. Leadership roles ranged from project leader to director of the ERC, and thus reflect autonomy and voice in the ERC. More autonomy and voice may have a significant impact on commitment to the organization that grants such benefits (Hackman \& Oldham, 1976). In addition to their conceptual links, all three variables were bivariately correlated with at least one form of commitment, making them important to include as controls in our models (Becker, 2005).

\subsection{Statistical Analyses}

First, we calculated power using Monte Carlo simulation with 500 samples in Mplus (MacCallum, Browne, \& Sugawara, 1996; Preacher, 2015) for each dependent variable. For organizational commitment, the power for detecting a three-way interaction at the between-level was 24 percent and for professional commitment, it was 13 percent. According to Dawson and Richter (2006), when power is above $5 \%$, the detection of moderation effects is reliable. Thus, we proceeded with our preparatory analyses.

Next, although cross-level moderators minimize risk of common method variance influencing the results (Lai, Li, \& Leung, 2013), we followed Podsakoff, MacKenzie, and Podsakoff's (2012) recommendations to test for the effect of common method variance among our self-report variables by allowing every item to load on its respective construct and an uncorrelated latent variable (method factor). The variance explained by the method factor was $24 \%$, which is comparable to the $25 \%$ average in 
published studies (Williams, Cote, \& Buckley, 1989). We also conducted a full confirmatory factor analysis of our measurement model and all fit statistics were acceptable (see Appendix A; Hu \& Bentler, 1999). Finally, we calculated the Variance Inflation Factor (VIF) in SAS to determine if multicollinearity was a threat. VIF values ranged from 1.05 to 1.15 , well below the suggested cut-off of 10 (Belsley, Kuh, \& Welsch, 1980).

Before creating interaction terms, we centered innovation orientation and role significance using the grand mean. As participants were clustered in 22 different ERCs, we conducted an analysis of variance (ANOVA) to calculate the intraclass correlations (ICC[1]) for organizational and professional commitment (Bliese, 2000). The ANOVA models were significant at $p<.05$ and .10 , respectively $\left(F^{\prime} \mathrm{s}=\right.$ 1.85 and 1.45). ICC(1)'s were .07 and .04 , respectively, indicating enough variance was attributable to ERC membership to warrant using multilevel, mixed-effects modeling in SAS PROC Mixed for hypothesis testing (Aguinis \& Culpepper, 2015). We tested each hypothesis using a multi-step approach to assess the unique effect of each set of predictors. We calculated Pseudo $R^{2}$ for each model, which reflects the within- and between-ERC variance in the dependent variables attributed to the predictors (Kreft \& de Leeuw, 1998).

\section{Results}

We present descriptive statistics, correlations, and reliabilities of study variables in Table 1. Innovation orientation was positively associated with both organizational commitment and professional commitment, as expected. Consistent with Wallace's (1993) meta-analysis, organizational and professional commitment were also positively correlated $(r=.15, p<.05)$.

Table 2 reports the results for Hypotheses 1 through 4 (main effects and two-way interactions). As shown in Step 1, innovation orientation was positively associated with both organizational and professional commitment, fully supporting Hypotheses 1 and 2 (Pseudo $R^{2}=.05$ for both outcomes). In Step 2, ERC productivity was not a significant main effect for either outcome. In Step 3, the innovation orientation $\times$ ERC productivity two-way interaction was not significant in predicting organizational 
commitment, failing to support Hypothesis 3 (Pseudo $R^{2}=.06$ ), but it was significant in predicting professional commitment (Hypothesis 4; Pseudo $R^{2}=.06$ ). 


\section{Table 1}

\section{Descriptive Statistics and Correlations}

\begin{tabular}{|c|c|c|c|c|c|c|c|c|c|c|}
\hline Variables & Mean & SD & 1 & 2 & 3 & 4 & 5 & 6 & 7 & 8 \\
\hline 1. Organizational commitment & 5.44 & 1.18 & $(.94)$ & $.13^{*}$ & & .07 & $.13^{*}$ & $.53 * *$ & & $.17 *$ \\
\hline 2. Professional commitment & 6.16 & 0.66 & $.15^{*}$ & $(.87)$ & & $.16^{* *}$ & .05 & $.16^{*}$ & & $.22 * *$ \\
\hline 3. ERC age & 5.25 & 2.87 & -.08 & .11 & - & & & & & \\
\hline 4. Gender & 0.80 & .40 & .08 & $.15^{* *}$ & -.07 & - & .06 & $.19 * *$ & & .11 \\
\hline 5. Leadership status & 0.64 & .48 & $.13 *$ & .06 & .10 & .06 & - & $.24 * *$ & & $.13 *$ \\
\hline 6. Role significance & 6.16 & 1.05 & $.55^{* *}$ & $.14^{*}$ & $-.13 *$ & $.19 * *$ & $.22 * *$ & $(.87)$ & & $.17 * *$ \\
\hline 7. ERC productivity & 7.80 & 15.96 & .07 & .04 & $.16^{*}$ & .03 & .08 & -.01 & - & \\
\hline 8. Innovation orientation & 5.51 & 0.72 & $.19 * *$ & $.23 * *$ & .03 & $.13 *$ & $.13 *$ & $.21 * *$ & .04 & $(.71)$ \\
\hline
\end{tabular}

Note. $\mathrm{N}=255$ across 22 ERCs. Average within-ERC correlations are reported above the diagonal for individual-level constructs (shaded cells denote Level-2 variables that do not have within-ERC correlations). Overall correlations without considering ERC affiliation are reported below the diagonal. Coefficient alphas reported on diagonal. All self-report variables measured with a 7-point response scale. ICC(1)'s: organizational commitment $=.07$ and professional commitment $=.04 . * p \leq .05, * * p \leq .01$. 
Table 2

Multilevel Modeling Results for Main Effects and Two-Way Interaction Predicting Commitment

\begin{tabular}{|c|c|c|}
\hline \multirow[b]{2}{*}{ Predictor Variables } & \multicolumn{2}{|c|}{ Criterion Variables } \\
\hline & $\begin{array}{l}\text { Organizational } \\
\text { Commitment } \\
\text { (Model 1) }\end{array}$ & $\begin{array}{c}\text { Professional } \\
\text { Commitment } \\
(\text { Model 2) }\end{array}$ \\
\hline \multicolumn{3}{|l|}{ STEP 1 (Hypotheses 1 and 2) } \\
\hline \multicolumn{3}{|l|}{ Controls } \\
\hline Intercept & $5.36^{* *}(4.78,5.95)$ & $5.80^{* *}(5.53,6.07)$ \\
\hline ERC Age & $-.04(-0.11,0.03)$ & $.03^{*}(0.0001,0.06)$ \\
\hline Gender & $.14(-0.21,0.49)$ & $.23^{*}(0.03,0.42)$ \\
\hline Leadership Status & $.27^{\dagger}(-0.03,0.56)$ & $.02(-0.15,0.18)$ \\
\hline \multicolumn{3}{|l|}{ Independent Variables } \\
\hline Innovation Orientation (A) & $.26^{* *}(0.06,0.46)$ & $.19^{* *}(0.08,0.30)$ \\
\hline Pseudo $R^{2}$ & .05 & .05 \\
\hline \multicolumn{3}{|l|}{ STEP 2} \\
\hline \multicolumn{3}{|l|}{ Controls } \\
\hline Intercept & $5.32^{* *}(4.75,5.89)$ & $5.79^{* *}(5.52,6.06)$ \\
\hline ERC Age & $-.02(-0.09,0.05)$ & $.03^{*}(0.002,0.06)$ \\
\hline Gender & $.15(-0.20,0.50)$ & $.23^{*}(0.03,0.43)$ \\
\hline Leadership Status & $.28^{\dagger}(-0.02,0.57)$ & $.02(-0.15,0.18)$ \\
\hline \multicolumn{3}{|l|}{ Independent Variables } \\
\hline Innovation Orientation (A) & $.26^{* *}(0.06,0.46)$ & $.19^{* *}(0.08,0.30)$ \\
\hline ERC Productivity (B) & $-.01(-0.01,0.00003)$ & $-.001(-0.004,0.002)$ \\
\hline Pseudo $R^{2}$ & .06 & .05 \\
\hline$\Delta R^{2}$ & .01 & .00 \\
\hline \multicolumn{3}{|l|}{ STEP 3} \\
\hline \multicolumn{3}{|l|}{ Controls } \\
\hline Intercept & $5.33^{* *}(4.76,5.90)$ & $5.81^{* *}(5.54,6.07)$ \\
\hline ERC Age & $-.02(-0.09,0.05)$ & $.03^{*}(0.003,0.06)$ \\
\hline Gender & $.15(-0.20,0.50)$ & $.23^{*}(0.04,0.43)$ \\
\hline Leadership Status & $.27^{\dagger}(-0.02,0.56)$ & $.004(-0.16,0.17)$ \\
\hline \multicolumn{3}{|l|}{ Independent Variables } \\
\hline Innovation Orientation (A) & $.24^{*}(0.03,0.45)$ & $.16^{* *}(0.04,0.27)$ \\
\hline ERC Productivity (B) & $-.01^{*}(-0.01,-0.0002)$ & $-.002(-0.01,0.001)$ \\
\hline $\mathrm{A} \times \mathrm{B}$ & $.002(-0.01,0.01)$ & $.004^{*}(0.0002,0.01)$ \\
\hline Pseudo $R^{2}$ & .06 & .06 \\
\hline$\Delta R^{2}$ & .00 & .01 \\
\hline
\end{tabular}

Note. $95 \%$ Confidence Interval Limits reported in parentheses after unstandardized regression coefficients. Pseudo $R^{2}$ values indicate percentage of the total variance (i.e., both between and within group variance) in the dependent variable accounted by all the variables in the model together (Kreft $\&$ de Leeuw, 1998). ${ }^{\dagger} p \leq .10 ;{ }^{*} p \leq .05 ;{ }^{* *} p \leq .01$. 
We proceeded to plot two simple slopes at +/- 1 SD of ERC productivity to detect the form of the interaction for professional commitment (see Figure 1; Dawson \& Richter, 2006; Stone \& Hollenbeck, 1989). The simple slopes were significantly positive for both mean and high levels of ERC productivity, (slopes $=.19$ and .26 for low and high productivity, respectively; $p \leq .001)$ and positive at $p=.07$ for low levels of ERC productivity (slope $=.13$ ). Overall, this pattern of results did not support our predictions; thus, Hypothesis 4 was not supported.

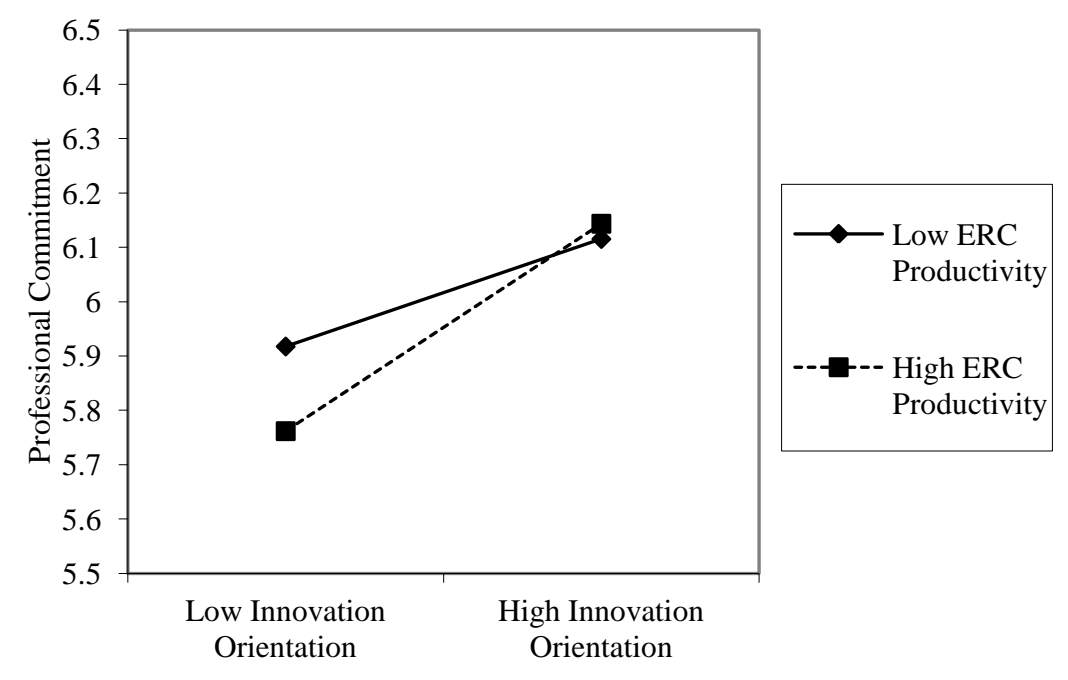

Figure 1. Innovation Orientation $\times$ ERC Productivity Predicting Professional Commitment

Next, we tested Hypothesis 5 (three-way interaction predicting organizational commitment) and Hypothesis 6 (professional commitment; see Table 3). First, we modeled organizational commitment as the criterion. In Step 1, we entered the main effects and control variables. Only ERC productivity and role significance predicted organizational commitment (Pseudo $R^{2}=.30$ ). Contrary to expectations, ERC productivity was negatively associated with organizational commitment, however (supporting the importance of considering the higher-order interaction terms to better understand the model). In Step 2, we entered all two-way interaction terms; none were significant. In Step 3, we entered the three-way interaction term, which was significant $(b=.01, p<.05)$ and accounted for an additional two percent of the variance in the criterion (Pseudo $R^{2}=.32$ ). 
Table 3

Multilevel Modeling Results for Three-Way Interactions Predicting Commitment

\begin{tabular}{|c|c|c|}
\hline \multirow[b]{2}{*}{ Predictor Variables } & \multicolumn{2}{|c|}{$\begin{array}{c}\text { Criterion Variables } \\
\end{array}$} \\
\hline & $\begin{array}{l}\text { Organizational } \\
\text { Commitment } \\
(\text { Model 1) } \\
\end{array}$ & $\begin{array}{c}\text { Professional } \\
\text { Commitment } \\
(\text { Model 2) }\end{array}$ \\
\hline \multicolumn{3}{|l|}{ STEP 1} \\
\hline \multicolumn{3}{|l|}{ Controls } \\
\hline Intercept & $5.51^{* *}(5.04,5.98)$ & $5.79^{* *}(5.52,6.07)$ \\
\hline ERC Age & $-.004(-0.05,0.06)$ & $0.04^{*}(0.01,0.10)$ \\
\hline Gender & $-.12(-0.43,0.18)$ & $.21 *(0.01,0.42)$ \\
\hline Leadership Status & $-.01(-0.27,0.25)$ & $-.01(-0.18,0.16)$ \\
\hline \multicolumn{3}{|l|}{ Independent Variables } \\
\hline Innovation Orientation (A) & $0.13(-0.05,0.30)$ & $0.18^{* *}(0.07,0.29)$ \\
\hline ERC Productivity (B) & $-0.01^{* *}(-0.01,-0.002)$ & $-0.001(-0.004,0.002)$ \\
\hline Role significance $(\mathrm{C})$ & $0.60^{* *}(0.48,0.73)$ & $0.06(-0.02,0.15)$ \\
\hline Pseudo $R^{2}$ & .30 & .05 \\
\hline \multicolumn{3}{|l|}{ STEP 2} \\
\hline \multicolumn{3}{|l|}{ Controls } \\
\hline Intercept & $5.50^{* *}(5.01,5.99)$ & $5.80^{* *}(5.53,6.07)$ \\
\hline ERC Age & $0.01(-0.05,0.06)$ & $0.03^{*}(0.01,0.06)$ \\
\hline Gender & $-.12(-0.43,0.18)$ & $.23 *(0.03,0.43)$ \\
\hline Leadership Status & $-.01(-0.27,0.25)$ & $-.01(-0.18,0.16)$ \\
\hline \multicolumn{3}{|l|}{ Independent Variables } \\
\hline Innovation Orientation (A) & $0.10(-0.09,0.29)$ & $0.15^{* *}(0.03,0.27)$ \\
\hline ERC Productivity (B) & $-0.01^{*}(-0.01,-0.001)$ & $-0.003^{\dagger}(-0.01,0.0002)$ \\
\hline Role significance $(\mathrm{C})$ & $0.63^{* *}(0.50,0.77)$ & $0.03(-0.06,0.12)$ \\
\hline $\mathrm{A} \times \mathrm{B}$ & $0.004(-0.004,0.01)$ & $0.002(-0.004,0.01)$ \\
\hline $\mathrm{A} \times \mathrm{C}$ & $-0.002(-0.18,0.18)$ & $0.05(-0.07,0.17)$ \\
\hline $\mathrm{B} \times \mathrm{C}$ & $0.01(-0.01,0.004)$ & $0.004(-0.001,0.01)$ \\
\hline Pseudo $R^{2}$ & .30 & .06 \\
\hline$\Delta R^{2}$ & .00 & .01 \\
\hline \multicolumn{3}{|l|}{ STEP 3} \\
\hline \multicolumn{3}{|l|}{ Controls } \\
\hline Intercept & $5.54^{* *}(5.04,6.04)$ & $5.77^{* *}(5.50,6.03)$ \\
\hline ERC Age & $0.01(-0.05,0.07)$ & $0.03^{*}(0.01,0.06)$ \\
\hline Gender & $-.17(-0.47,0.14)$ & $.26^{* *}(0.06,0.46)$ \\
\hline Leadership Status & $.01(-0.25,0.27)$ & $-.03(-0.20,0.14)$ \\
\hline \multicolumn{3}{|l|}{ Independent Variables } \\
\hline Innovation Orientation (A) & $0.13(-0.05,0.32)$ & $0.13^{*}(0.01,0.25)$ \\
\hline ERC Productivity (B) & $-0.01^{* *}(-0.02,-0.003)$ & $-0.001(-0.004,0.003)$ \\
\hline Role significance $(\mathrm{C})$ & $0.65^{* *}(0.51,0.78)$ & $0.02(-0.07,0.11)$ \\
\hline $\mathrm{A} \times \mathrm{B}$ & $0.001(-0.01,0.01)$ & $0.004(-0.001,0.01)$ \\
\hline $\mathrm{A} \times \mathrm{C}$ & $-0.09(-0.28,0.11)$ & $0.12^{\dagger}(-0.01,0.24)$ \\
\hline $\mathrm{B} \times \mathrm{C}$ & $-0.01^{\dagger}(-0.02,0.001)$ & $0.01^{*}(0.0004,0.01)$ \\
\hline
\end{tabular}




\begin{tabular}{rcc}
\hline $\mathrm{A} \times \mathrm{B} \times \mathrm{C}$ & $0.01^{*}(0.002,0.02)$ & $-0.01^{* * *}(-0.02,-0.003)$ \\
Pseudo $R^{2}$ & .32 & .09 \\
$\Delta R^{2}$ & .02 & .03 \\
\hline
\end{tabular}

Note. $95 \%$ Confidence Interval Limits reported in parentheses after unstandardized regression coefficients. Pseudo $R^{2}$ values indicate percentage of the total variance (i.e., both between and within group variance) in the dependent variable accounted by all the variables in the model together (Kreft $\&$ de Leeuw, 1998). ${ }^{\dagger} p \leq .10 ;{ }^{*} p \leq .05 ;{ }^{* *} p \leq .01$.

Upon conducting the same three steps for professional commitment, we found that innovation orientation was significant in Step $1(b=.18, p<.01)$, as were the ERC age and gender control variables. In Step 2, no two-way interaction terms were significant. In Step 3, the three-way interaction term was significant $(b=-.01, p<.05)$ and accounted for three percent of unique variance in the criterion (Pseudo $\left.R^{2}=.09\right)$. These results provided initial support for Hypotheses 5 and 6 .

Next, we plotted four simple slopes for each combination of ERC productivity and role significance (using cutoffs at +/- 1 SD of each moderator; Dawson \& Richter, 2006; Stone \& Hollenbeck, 1989). As seen in Figure 2, the overall level of organizational commitment was highest and professional commitment was lowest among individuals reporting high role significance working in highly productive ERCs (condition 1). This group also exhibited the strongest positive slope for organizational commitment and strongest negative slope for professional commitment (see Table 4 for simple slopes and slope difference tests). The innovation orientation-organizational commitment relationship was also significantly positive among individuals reporting low role significance working in highly productive ERCs (condition 2), but lower and weaker overall compared to higher role significance. These results supported our predictions. Individuals working in less productive ERCs (conditions 3 and 4) exhibited the lowest levels of organizational commitment and highest levels of professional commitment, regardless of role significance. Although these low conditions did not exhibit significant slopes, they did exhibit lower levels of commitment as expected. Thus, Hypotheses 5 and 6 were largely supported. 
Table 4

Simple Slopes and Slope Difference Tests for Three-way Interactions

\begin{tabular}{|c|c|c|c|c|}
\hline \multirow{2}{*}{$\begin{array}{ll} & \text { Group } \\
\text { Simple Slopes } & \end{array}$} & \multicolumn{2}{|c|}{$\begin{array}{c}\text { Organizational } \\
\text { Commitment }\end{array}$} & \multicolumn{2}{|c|}{$\begin{array}{l}\text { Professional } \\
\text { Commitment }\end{array}$} \\
\hline & Slope & $t$ & Slope & $t$ \\
\hline (1) High ERC Productivity, High Role Significance & 2.44 & $2.13^{*}$ & -1.45 & $-1.76^{\dagger}$ \\
\hline (2) High ERC Productivity, Low Role Significance & 1.78 & $2.20^{*}$ & -0.95 & $-1.62^{\dagger}$ \\
\hline (3) Low ERC Productivity, High Role Significance & -1.69 & $-1.65^{\dagger}$ & 2.02 & $2.96^{* *}$ \\
\hline (4) Low ERC Productivity, Low Role Significance & -1.16 & $-1.62^{\dagger}$ & 1.45 & $3.02^{* *}$ \\
\hline Slope Differences & & $t$ & & $t$ \\
\hline (1) and (2) & & $1.93^{\dagger}$ & & $-2.07^{*}$ \\
\hline (1) and (3) & & $2.36^{*}$ & & $-2.77^{* *}$ \\
\hline (1) and (4) & & $2.37^{*}$ & & $-2.64^{* *}$ \\
\hline (2) and (3) & & $2.35^{*}$ & & $-2.82^{* * *}$ \\
\hline (2) and (4) & & $2.40^{*}$ & & $-2.72^{* * *}$ \\
\hline (3) and (4) & & $-1.72^{\dagger}$ & & $2.78^{* *}$ \\
\hline
\end{tabular}

Note. $\dagger \mathrm{p} \leq .10 ;{ }^{*} p<.05 ;^{* *} p<.01$. 

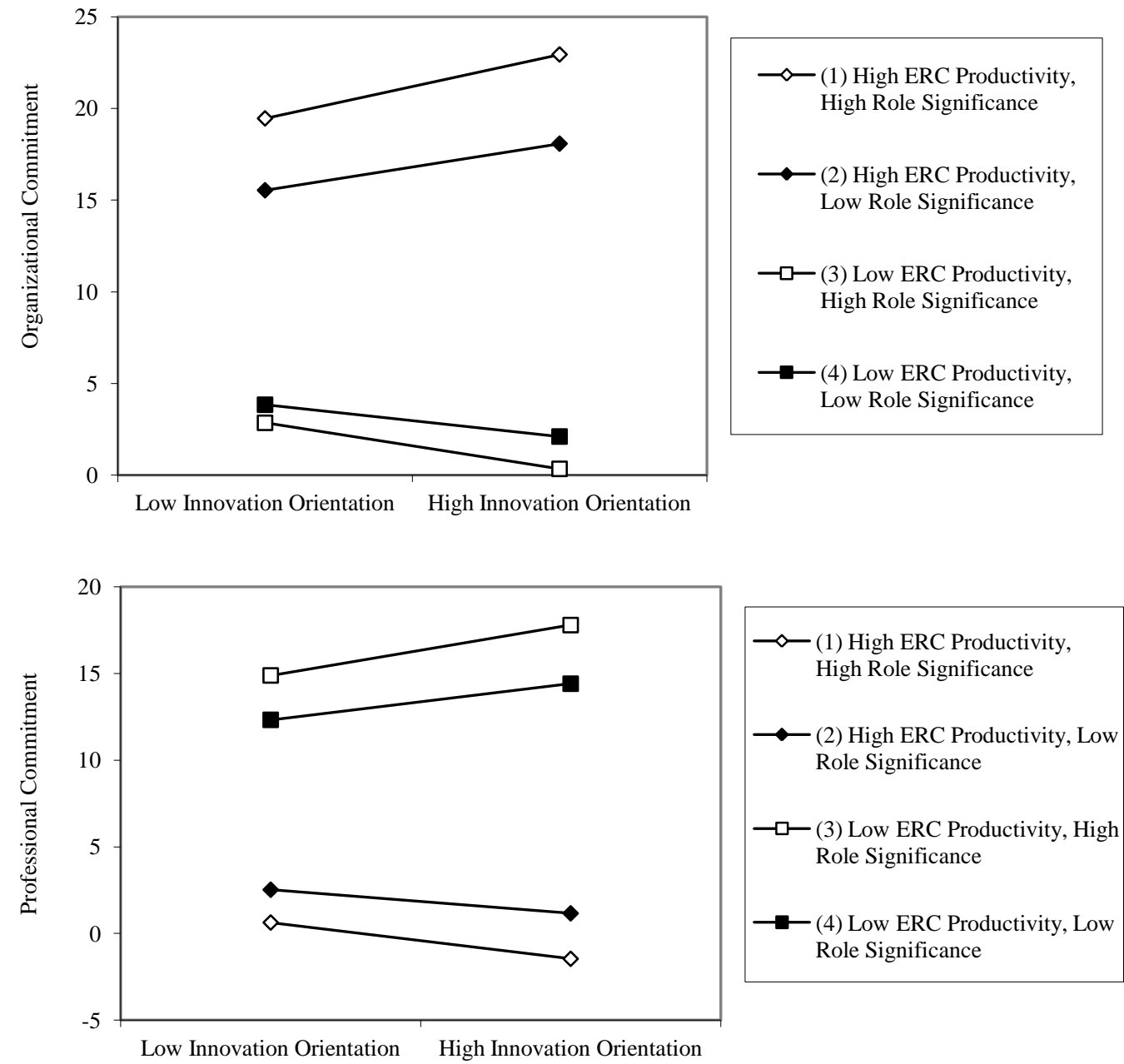

Figure 2. Innovation Orientation $\times$ ERC Productivity $\times$ Role Significance Predicting Commitment.

\subsection{Post-hoc Analyses}

To more deeply examine these results, we conducted two sets of post-hoc analyses. First, we explored whether one technology transfer output may be driving the results of the overall sum of ERC productivity. We conducted the same analyses reported for Hypotheses 5 and 6 for each individual technology transfer output - standards, licenses, and jobs created. The only model with a significant three-way interaction was jobs created predicting organizational commitment $(b=.03, p=.02)$. We plotted this interaction using the same procedures as above, which revealed a generally consistent pattern as above (see Figure 3). All slopes were significant at $p<.05$, and all slopes were significantly different 
from all other groups, supporting the main results of this study. The results for professional commitment may have been non-significant because of the lower variance accounted for by the full model (9\%) and overall lower statistical power available (13\%) to detect a smaller effect size for each individual technology transfer output.

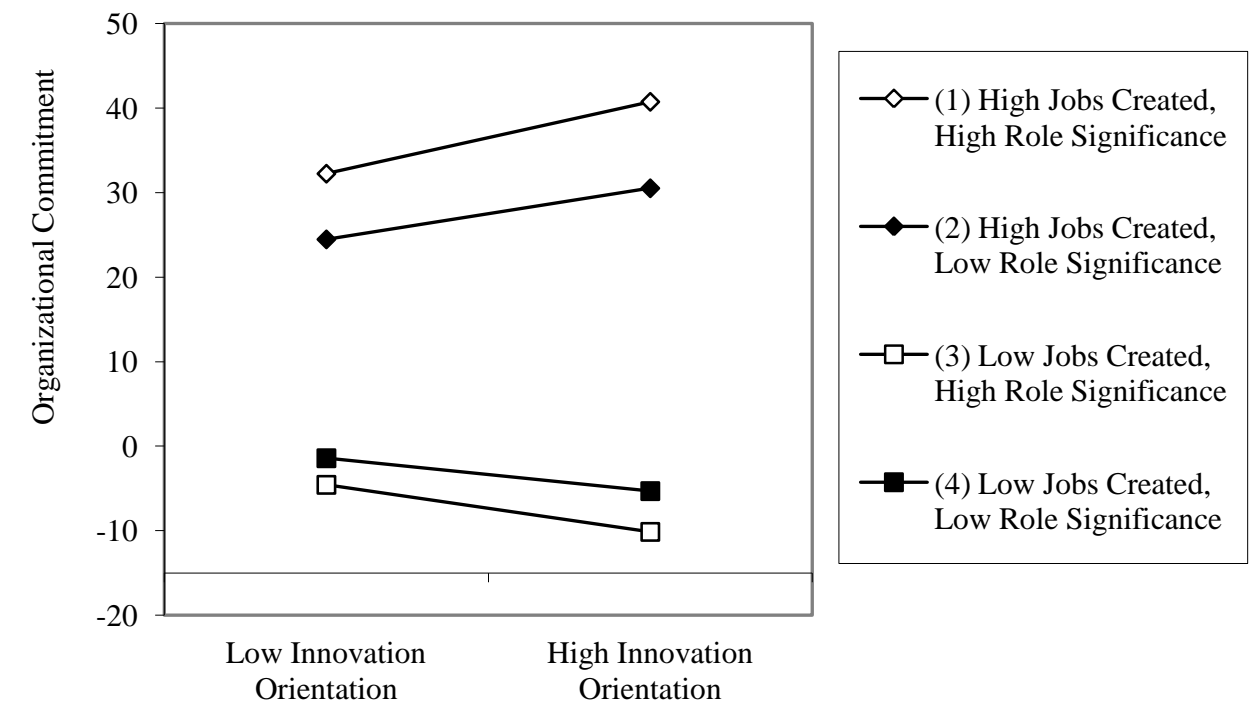

Figure 3. Post-hoc Analysis - Innovation Orientation $\times$ Jobs Created $\times$ Role Significance Predicting Commitment.

As a second post-hoc analysis, we explored differences between commitment profiles to better understand the implications of these results for Tuma and Grimes' (1981) predictions and theory on dual allegiance, based on a priori groupings of the two forms of commitment. Using high and low cutoffs at the mean $+/-1 / 2$ SD for each type of commitment, we created nine profiles: (1) high organizational and professional commitment ("high-high"), (2) high organizational, low professional commitment (“highlow”), (3) low organizational, high professional commitment ("low-high"), (4) low organizational and professional commitment ("low-low"), (5) high organizational, moderate professional commitment ("high-mod"), (6) low organizational, moderate professional commitment ("low-mod"), (7) moderate organizational, high professional commitment (“mod-high"), (8) moderate organizational, low professional commitment ("mod-low"), and (9) moderate organizational and professional commitment ("mod-mod"). Out of the total 255 participants, 87 were in one of the first four commitment profile groups with high and/or low levels of both forms of commitment, and 95 participants were in one of the 
next four groups, in which only one form of commitment was extreme and the other was moderate. All others (73) were in the "mod-mod" profile, in which both forms of commitment were close to the mean.

We were first interested in levels of each predictor across commitment profiles. To test for differences, we conducted a two-way ANOVA with Tukey post-hoc comparisons for each predictor. The $F$ omnibus test was not significant $(F=0.85, n s)$ for ERC productivity, suggesting that ERC productivity was not significantly different across commitment profiles. We did, however, observe differences for both role significance $(F=11.34, p<.0001)$ and innovation orientation $(F=3.15, p=.002)$.

For role significance, the Tukey post-hoc comparisons revealed that three profiles were significantly different from at least one other profile. Most notably, the low-low and low-mod commitment profiles reported significantly lower role significance than all but two other profiles (lowhigh and each other). The low-high profile also reported significantly lower role significance than three other commitment profiles: high-high, high-mod, and mod-high. This suggests role significance may be even more important than the three-way interaction tests suggested; people who are lower in role significance appear to be less loyal to the organization and perhaps even the profession.

For innovation orientation, the Tukey post-hoc comparisons revealed that individuals in the highhigh commitment profile reported higher levels of innovation orientation than those in the low-low, lowmod, mod-low, or mod-mod commitment profiles. Thus, the most innovatively-oriented scientists and engineers may also be among the most loyal to both the profession and organization.

Next, we explored academic rank in conjunction with the nine commitment profiles. Rank is closely related to tenure and seniority in both the organization and the profession. Although academic rank was not significantly correlated with either form of commitment or the commitment profile variable (and thus not included as a control), frequency graphs of rank across commitment profiles revealed potentially important differences. First, associate and full professors most often reported moderate or high levels of both forms of commitment. These more senior ranks were not as likely to report extreme levels of just one form of commitment or low levels of both forms of commitment, but rather they were generally high to moderate in both, suggesting they tend to direct loyalty to both the organization and the 
profession. In contrast, assistant professors were most likely to report either high levels of both forms of commitment, or high levels of professional and low levels of organizational commitment. The next most frequent profiles included moderate organizational commitment with either high or low professional commitment. In general, these junior faculty were more likely to report extreme levels (high or low commitment), which suggests they may be less balanced in their loyalties, and they may be more likely to experience low levels of either form of commitment than more senior academics. Perhaps some of this extremity is due to career stage; members newer to the organization than the profession may have identified more strongly with the profession to this point in their careers (through graduate school and into their first jobs). They may also still be learning the balance of the organization and the profession, including how they are involved with each. Leaders of research centers who are attuned to these possibilities may better engender loyalty from these junior innovators.

\section{Discussion}

In an era when innovation is vital to economic prosperity, we explored factors that may be associated with organizational and professional commitment among the innovators. We suggest leaders who understand how to manage commitment to multiple foci (i.e., dual allegiance) may be most successful at motivating and retaining this highly valued workforce (Mathieu \& Zajac, 1990). We tested a multi-level, multi-source model that explored the interplay of individual innovation orientation, organizational productivity, and role significance, which aligned with Allen and Meyer's (1997) typology of commitment antecedents - individual factors, organizational factors, and work experiences, respectively. Innovatively-oriented ERC scientists and engineers reported higher levels of both organizational and professional commitment, supporting previous meta-analytic work on the positive correlation between these two forms of commitment (Wallace, 1993). The significant three-way interactions suggest, however, that highly innovative scientists and engineers may be most committed to working in ERCs that make a larger impact in the form of later-stage technology transfer (i.e., licenses, industry standards, jobs created), especially when those individuals recognize their personal contribution to that impact (role significance). These same individuals may be less committed to their profession. But 
for less productive ERCs, we found non-significant associations between innovation orientation and both forms of commitment; in these conditions, participants reported lower overall levels of organizational commitment and higher levels of professional commitment.

The hypothesized two-way interactions were not supportive of our hypotheses. We attribute this inconsistency to the importance of considering role significance in the model; both the three-way interactions and our post-hoc analyses reinforced this. Namely, we found that the most loyal individuals (to both profession and organization) may be those who report higher role significance, higher innovation orientation, and have been in the profession longer (associate or full professors). We also found an unexpected negative main effect of ERC productivity on organizational commitment, which we also believe represents an incomplete picture because the effects of innovation orientation and ERC productivity are contingent on role significance (Hypotheses 5 and 6). This could, however, suggest a further "shifting" of dual allegiance as an innovator's perception of fit with the ERC and beyond evolves. In particular, when one's work is successfully applied outside the ERC, attention may then shift to the marketplace, where "cool" new products are created with new technology, or even to the start-up company and the innovative jobs it offers. Indeed, these external environments may offer even more exciting behavioral feedback (Tuma \& Grimes, 1981), which may drive further changes in one's commitment to the ERC. This is a potential avenue for future research.

\subsection{Theoretical Implications}

These results have a number of implications, which contribute to the extant literature. First, these results add to an emerging body of research on individual differences among scientists and engineers (e.g., Keller, 2012; Roach \& Sauermann, 2010; Sauermann \& Cohen, 2010). Individual orientations are a good starting point for better understanding these unique, highly-valued employees because they are largely stable and determine preferences, values, and tendencies (Barrick \& Mount, 2005). Innovation orientation is particularly important for the researchers responsible for the next generation of innovations. But innovativeness also represents a potential challenge to managers regarding how to garner commitment among individuals who do not easily conform to organizational norms and structures (Dietz 
\& Bozeman, 2005; Robinson et al., 1991) and are not as easily motivated by traditional rewards (e.g., pay; Burton \& O’Reilly, 2004; Lam, 2011). Our results suggest that scientists' and engineers' individual orientation toward innovative behaviors may be positively associated with both organizational and professional commitment, especially when the organization is successful in producing impactful technology transfer and their individual contribution is emphasized. The joint effects of our predictors revealed a negative relationship between innovation orientation and professional commitment when ERC productivity was high, however. Therefore, our results suggest it is possible to foster both organizational and professional commitment among innovators, but further research is needed on the mechanisms for doing so, including the role of person-organization fit, cognitive congruence, and organizational/professional selection priorities (Kristof-Brown et al., 2005; Tuma \& Grimes, 1981). Perhaps counterintuitively, our post-hoc analyses also suggested that the innovatively-oriented individuals may indeed be the most committed to both their organization and profession.

The boundary conditions we uncovered constitute our second theoretical contribution. We observed positive organizational commitment and negative professional commitment associations with innovation orientation only in highly productive organizations, but this depended also on role significance (i.e., the three-way interactions provided the most insight). When technology transfer productivity was low, overall levels of organizational commitment were lower and overall levels of professional commitment were higher, and both were unrelated to individual innovativeness. Overall, these results suggest that innovative individuals may be most embedded in the organization and least embedded in their profession when they work in an ERC that is successful in later-stage technology transfer activities. Results were similar for individuals who had high or low role significance, although individuals with high role significance may be slightly more affected by working in ERCs producing high levels of technology transfer. Our post-hoc analyses suggested that individuals reporting higher levels of role significance also tended to be more committed to both the organization and profession. This supports the broader literature on the importance of employee involvement, enriched jobs, and alignment of goals for fostering employee commitment (e.g., Guest, 2002; Locke \& Latham, 2002; Marinova, Peng, Lorinkova, Van Dyne, \& 
Chiaburu, 2015; Pereira \& Osburn, 2007). In all, when the organization successfully meets its goals and managers communicate effectively about individual contributions to that success, loyalty from highly innovative researchers may shift toward that organization, and potentially away from the profession. Longitudinal research is needed to assess the actual shift of commitment in these conditions.

In addition to shedding light on two forms of commitment, our results also contribute to research on technology transfer and innovation. Building on strategic HRM research that explores employee attitudes, work factors, and organizational productivity in tandem (i.e., Guest, 2002), we explored outcomes of technology transfer, instead of considering technology transfer as only an outcome. We conceptualized our cross-level moderator, organizational (ERC) productivity, by focusing only on technology transfer outputs that represent tangible application of research findings outside the laboratory (i.e., licenses, industry standards, and new jobs created in spinoff companies). Perhaps this focus sets an example for future technology commercialization research in distinguishing between outputs that are simply steps in the commercialization pipeline (e.g., invention disclosures or patents) versus outputs that have traveled the commercialization pipeline and have been demonstrably applied outside the research laboratory. As Hackman and Oldham (1976) emphasized, meaningful work that clearly influences the lives of others may indeed affect individuals in terms of how they view themselves and their employing organization.

Finally, our results also highlight the importance of context and organizational forms in studying any phenomenon. It is unclear whether we would find the same results in an organization not designed or strategically positioned like an ERC. In our efforts to contribute to theory on MMURCs, and more generally, the hybrid organizational form, we also contribute to research on the organizational conditions for creative expression. Organizational norms may be different than professional norms, and these dynamics may affect organizationally- and professionally-targeted attitudes (Mainemelis, 2010; Schein, 1971). As MMURCs increase in prevalence, research such as the present study is crucial to helping leaders understand how to better manage the organization and the people within it (Corley et al., 2006).

\subsection{Practical Implications}


We suggest that leaders of scientists and engineers working in ERCs and similar research centers should emphasize strategy execution that results in a meaningful impact outside the research laboratory. One explanation for this is that it may simultaneously satisfy three types of motivation for scientists and engineers, namely extrinsic motivation (i.e., recognition and financial rewards), normative intrinsic motivation (i.e., "the individual's sense of compliance with personal and social norms"; Lam \& Lambermont-Ford, 2010, p. 53), and hedonic intrinsic motivation (i.e., satisfying one's own needs for creativity; Lam \& Lambermont-Ford, 2010; Lindenberg, 2001). Particularly when leaders communicate each individual's and team's role significance, with consideration for individual preferences for innovative tendencies, they may cultivate healthy levels of organizational commitment, although concerns about professional commitment arose. Future research is needed to assess whether these mechanisms could explain the effects we found.

Our results suggest that making a meaningful impact on society can positively influence the attitudes of employees (Hackman \& Oldham, 1976); this may be achieved by proper implementation of one's strategic plan. In the absence of clear success, leaders can emphasize small wins as they occur to help employees stay motivated and focused on the work of the organization.

Leaders who explicitly communicate about roles of individuals and their teams in the overall strategic plan implementation may also foster individual loyalty, especially if they also highlight the success of the organization. Leaders might do this by clearly communicating individual responsibilities in the larger organizational strategic plan, commending individuals on their importance to the organization, providing role-specific rewards, offering visible opportunities for advancement and notoriety, and generally ensuring that individuals feel valued. Although this may be accepted as common management practice in many workplaces, leaders of scientists and engineers may not always recognize or act on the importance of these "ego-building" efforts among these knowledge workers.

As leaders in research organizations try to capitalize on the innovative tendencies of their employees, they may wish to design policies and procedures that support preferences for creative, out-ofthe-box work styles. For example, flexible administrative policies and procedures that minimize 
bureaucracy may enable these employees to be most effective, particularly in pursuing innovative work. When bureaucracy cannot be minimized, managers might compensate by providing administrative support and protection from bureaucratic processes; this may engender innovation in such employees in spite of organizational constraints (Chang \& Choi, 2007). In their work on organizational expedience, Parks, Ma, and Gallagher (2010) suggested that people who experience psychological ownership are likely to produce more creative outputs as they are "allowed" to deviate from established norms. Mainemelis (2010) and Criscuolo, Salter, and Ter Wal (2014) also supported this; the most innovative workers are likely to deviate from manager's orders to pursue a creative idea they believe holds potential. Indeed, research shows that flexibility is critical to individual success in innovation (Conti et al., 2014). Together with our results, this work suggests that innovative employees, if managed properly in a successful organization, may be among the most loyal. By learning how to leverage nontraditional tendencies to the benefit of innovative work, managers may realize the best of both worlds in terms of innovative productivity, yet avoid other more harmful forms of rule-breaking, toward which some of these individuals might be inclined.

We also suggest that leaders try to foster a synergy between organizational and professional concerns, thus encouraging scientists and engineers to enhance both organizational and professional commitment (Kinnie \& Swart, 2012; Parks et al., 1998). We found that individuals higher on innovation orientation experienced less loyalty to their profession when they worked in a highly impactful organization and when they understood their role in that success. This may be particularly true for junior faculty, as our post-hoc analyses revealed. We suggest this may be due to a learning curve in balancing loyalties to both the organization and the profession, or higher stakes for pre-tenure faculty to impress certain "bosses." Waning professional commitment may have detrimental effects, such as weaker ties to the professional community for knowledge-sharing, employee referrals, and technology transfer assistance (Blau et al., 2003; Liebeskind et al., 1996). Although our data did not measure this directly, decreased professional commitment may be an indicator of evolving misfit in the professional and 
organizational domains ${ }^{2}$. Leaders are wise to remain sensitive to such possibilities, emphasizing individual's sense of belonging and value to the organization, while encouraging both organizational and professional citizenship and compatibility between those two communities (Solinger et al., 2013).

Fostering social networks that support the research aims of the organization while fulfilling an individual's need to belong in a broader professional community may be one way to do this, even if that professional community is different than the profession in which the person was trained (Liebeskind et al., 1996). Leaders paying attention to these dynamics may be best positioned to maximize the benefits of some form of professional commitment while fostering continued loyalty to the organization from their most innovative researchers.

In conclusion, it behooves leaders to understand individual goals, values, and predispositions to better manage, motivate, and retain their most valued employees. Together with successful strategy execution, a focus on making a meaningful societal impact, and clear communication about individual roles in organizational success, these considerations may position leaders to maximize organizational commitment and best leverage professional commitment. Although we studied ERCs specifically, MMURCs in general describe this type of hybrid research organization, and therefore the leaders of other types of research centers may also find value in this study.

\subsection{Strengths, Limitations, and Future Directions}

Although this study had a number of strengths, including a multi-source, multi-level design, with data from multiple time points in a relevant field sample, some limitations warrant caution regarding the conclusions. First, we cannot make causal claims about our results. For that we would need longitudinal survey data (ideally, several years), which would allow confidence about the direction of effects as well as assess shifting loyalties over time. Although we did look at past performance of ERCs (two years before the survey) and a stable individual difference construct (innovation orientation), causality is still a

\footnotetext{
${ }^{2}$ We should note that in a post-hoc Latent Profile Analysis (not reported here but requested by an anonymous reviewer during the review process), we found no combinations emerge in which professional commitment was below the mean, except in one profile, in conjunction with mean organizational commitment and high innovation orientation. (All other profiles had mean or high levels of professional commitment). This suggests that not enough researchers in our sample experienced high organizational commitment in conjunction with low professional commitment to be detected, and thus "waning" professional commitment is relative to the higher levels of this form of commitment generally observed. Future research is needed to better understand these dynamics.
} 
concern that can only be addressed by multiple data collections. Longitudinal data would also provide valuable insight into the behavioral feedback that may occur as organizations achieve success at varying rates (Tuma \& Grimes, 1981). We controlled for ERC age to partially address this issue but testing these propositions over several years as organizations mature would be most insightful.

Second, our sample of organizations was modest $(\mathrm{N}=22)$, reducing statistical power in our multi-level analyses (.24 for organizational commitment and .13 for professional commitment; Lavrakas, 2008). Still, Dawson and Richter (2006) suggest this is sufficient power to detect reliable (i.e., trustworthy) three-way interactions. Replication is desirable to confirm the conclusions of this or any study.

A third limitation may involve our ERC productivity measure, which was an aggregate of a number of different indicators of research being applied outside the laboratory across two years. As with any short-term metric, this does not accurately capture the actual impact of an ERC over time. It may also miss the intangible impact an ERC had on its surrounding industry or community, or other more finegrained forms of impact and progress in technology transfer activities. Thus, capturing more years and more forms of impact would be valuable in future research. Other indicators of innovation progress and other forms of organizational impact, such as minor milestones throughout the innovation process, behaviors indicative of research progress, customer perceptions, economic indicators, or the quality of the organization's impact on society, may be valuable in assessing the way an organization's work influences the attitudes of its employees, and vice versa (Harrison et al., 2006). Direction of organizational performance trajectory over extended periods of time may also reveal a clearer picture of organizational performance and impact on employees.

Impression management or affect may also have biased the results in some way, given the selfreport nature of role significance, innovation orientation, and commitment. However, our analyses indicated that common method variance was not likely a concern, and we did not detect a trend of positive affect bias in our pre-survey interviews. Indeed, we noticed quite a range of perceptions about how well-treated ERC members felt and how satisfied they were with their experiences. Still, we 
advocate for controlling for positive or negative affect or impression management in future studies. A related concern is that we dropped items from previously published and validated commitment scales, due to reliability concerns. This may have reduced our claim to using those validated scales, but our confirmatory factor analyses suggested a good fit of the revised scales (see Appendix A).

Finally, our conclusions may not readily generalize to non-ERC or non-MMURC contexts. The processes we studied may function differently among scientists and engineers who work in industry or other research organizations, as research has shown graduate students self-select into various occupations based on preferences for various job attributes and an innate "taste for science" (Roach \& Sauermann, 2010, p. 422). These processes may also function differently among other types of knowledge workers. However, the dynamics we uncovered provide some interesting insights for leaders in the academic setting and, in particular MMURCs, which are increasingly prevalent. We cautiously suggest our findings may also be of some value to managers of knowledge workers in other settings; although the contexts are different, the considerations may still be relevant and certainly are not likely to harm any organization.

Our post-hoc analyses of the theoretical predictors and academic rank across commitment profiles offer new directions for research in this area. Our data suggested that highly innovative, highly roleaware, more-senior academic researchers will be more likely to be moderately or highly committed to both the profession and organization. Future research should explore why this might be the case. Perhaps after one achieves tenure, one can pursue the intrinsic rewards associated with applying one's research outside the laboratory (i.e., impacting people's lives), even when this activity is not weighted as highly in rank and tenure systems (Dietz \& Bozeman, 2005; Lam, 2011). Also, Kreiner, Ashforth, and Sluss (2006) described the personal advantages and function of having a strong professional identity, no matter the occupation. Therefore, better understanding of the predictors of professional commitment in light of other types of commitment would be invaluable. Future research could also explore predictors of commitment profiles to better understand how to best foster multiple types of commitment.

Finally, we suggest building on these findings by exploring the underlying process of the development of professionally- and organizationally-oriented attitudes in scientists and engineers, and the 
relationships of those attitudes with retention, innovation performance, and organizational climate. Other personality traits may differentially influence these processes (e.g., openness to experience and other aspects of entrepreneurial orientation; e.g., Robinson et al., 1991) as well as other job or organizational factors designed to foster or inhibit innovative behaviors (e.g., role creation and innovation or autonomy; Hackman \& Oldham, 1976; Mainemelis, 2010; Schein, 1971). In all, this line of research has the potential to make a significant impact on the management of innovation as the work continues to shed insight into the quandary of how to motivate, retain, and effectively manage this unique population of employees, which is vital to future economic prosperity. 
Acknowledgements: This material is based upon work supported by the National Science Foundation under Grant No. EEC-0345195. We thank Lynn Preston and Linda Parker of the National Science Foundation for support and guidance of this research. We also thank Mary Sommers Pyne and Timmie Wang at the Rice Alliance for Technology and Entrepreneurship at Rice University for their assistance. 


\section{References}

Abramis, D. J., 1994. Work role ambiguity, job satisfaction, and job performance: Meta-analyses and review. Psychological Reports, 75, 1411-1433.

Aguinis, H., Culpepper, S. A., 2015. An expanded decision-making procedure for examining cross-level interaction effects with multilevel modeling. Organizational Research Methods, 18, 155-176.

Allen, N. J., Meyer, J. P., 1990. The measurement and antecedents of affective, continuance, and normative commitment to the organization. Journal of Occupational Psychology, 63, 1-18.

Allen, N. J., Meyer, J. P., 1996. Affective, continuance, and normative commitment to the organization: An examination of construct validity. Journal of Vocational Behavior, 49, 252-276.

Barrick, M. R., Mount, M. K., 2005. Yes, personality matters: Moving on to more important matters. Human Performance, 18, 359-372.

Becheikh, N., Landry, R., Amara, N., 2006. Lessons from innovation empirical studies in the manufacturing sector: A systematic review of the literature from 1993-2003. Technovation, 26, 644-664.

Becker, T. E., 2005. Potential problems in the statistical control of variables in organizational research: A qualitative analysis with recommendations. Organizational Research Methods, 8, 274-289.

Beede, D. Julian, T., Langdon, D., McKittrick, G., Khan, B., Doms, M., 2011. Women in STEM: A gender gap to innovation. U.S. Department of Commerce, Economics and Statistics Division. Retrieved 1/5/2016 from http://files.eric.ed.gov/fulltext/ED523766.pdf.

Belsley, D. A., Kuh, E., Welsch, R. E., 1980. Regression Diagnostics: Identifying Influential Data and Sources of Collinearity. New York: John Wiley and Sons.

Blau, G., Surges Tatum, D., Ward-Cook, K., 2003. Correlates of professional versus organizational withdrawal cognitions. Journal of Vocational Behavior, 63, 72-85.

Bliese, P. D., 2000. Within-group agreement, non-independence, and reliability: Implications for data aggregation and analysis, in: Klein, K.J., Kozlowski, S.W. (Eds.), Multilevel theory, research, and methods in organizations. Jossey-Bass, San Francisco, pp. 349-381. 
Boardman, P.C., Bozeman, B., 2006. Implementing a 'bottom-up,' multi-sector research collaboration: The case of the Texas Air Quality Study. Economics of Innovation \& New Technology, 15, 5169.

Boardman, C, Bozeman, B., 2007. Role strain in university research centers. Journal of Higher Education, 78, 430-463.

Bray, S. R., Brawley, L. R., 2002. Role efficacy, role significance, and role performance effectiveness. Small Group Research, 33, 233-253.

Burton, M. B., O'Reilly, C., 2004. The impact of high commitment values and practices on technology start-ups. Unpublished manuscript. Retrieved 2/26/2015 from http://digitalcommons.ilr.cornell.edu/cgi/viewcontent.cgi?article=1098\&context=workingpapers.

Chang, J., Choi, J., 2007. The dynamic relation between organizational and professional commitment of highly educated research and development professionals. Journal of Social Psychology, 147, 299316.

Choi, J. N., Chang, J. Y., 2009. Innovation implementation in the public sector: An integration of institutional and collective dynamics. Journal of Applied Psychology, 94, 245-253.

Conti, R., Gambardella, A., Mariani, M., 2014. Learning to be Edison: Inventors, organizations, and breakthrough inventions. Organization Science, 25, 833-849.

Corley, E. A., Boardman, P. C., Bozeman, B., 2006. Design and the management of multi-institutional research collaborations: Theoretical implications from two case studies. Research Policy, 35, 975993.

Criscuolo, P., Salter, A., Ter Wal, A. L. J., 2014. Going underground: Bootlegging and individual innovative performance. Organization Science, 25, 1287-1305.

Dawson, J. F., Richter, A. W., 2006. Probing three-way interactions in moderated multiple regression: Development and application of a slope difference test. Journal of Applied Psychology, 91, 917926. 
Dietz, J. S., Bozeman, B., 2005. Academic careers, patents, and productivity: industry experience as scientific and technical human capital. Research Policy, 34, 349-367.

Fichman, R. G, 2001. The role of aggregation in the measurement of IT-related organizational innovation. MIS Quarterly, 25, 427-455.

Fried, Y., Ferris, G. R., 1987. The validity of the job characteristics model: A review and meta-analysis. Personnel Psychology, 40, 287-322.

Goldberg, L. R., Johnson, J. A., Eber, H. W., Hogan, R., Ashton, M. C., Cloninger, C. R., Gough, H. C., 2006. The International Personality Item Pool and the future of publicdomain personality measures. Journal of Research in Personality, 40, 84-96. doi: 10.1016/j.jrp.2005.08.007

Guest, D., 2002. Human resource management, corporate performance and employee wellbeing: Building the worker into HRM. The Journal of Industrial Relations, 44, 335-358.

Hackman, J. R., Oldham, G. R., 1976. Motivation through the design of work: Test of a theory. Organizational Behavior \& Human Performance, 16, 255-279.

Harrison, D. A., Newman, D. A., Roth, P. L., 2006. How important are job attitudes? Meta-analytic comparisons of integrative behavioral outcomes and time sequences. Academy of Management Journal, 49, 305-325.

Hogan, R., 2005. In defense of personality measurement: New wine for old whiners. Human Performance, 18, 331-341.

Hu, L., Bentler, P. M., 1999. Cutoff criteria for fit indexes in covariance structure analysis: Conventional criteria versus new alternatives. Structural Equation Modeling, 6, 1-55.

Hunter, E. M., Perry, S. J., Currall, S. C., 2011. Inside multi-disciplinary science and engineering research centers: The impact of organizational climate on disclosures and patents. Research Policy, 40, 1226-1239. 
Keller, R. T., 1997. Job involvement and organizational commitment as longitudinal predictors of job performance: A study of scientists and engineers. Journal of Applied Psychology, 82, 539-545.

Keller, R. T., 2012. Predicting the performance and innovativeness of scientists and engineers. Journal of Applied Psychology, 97, 225-233.

Kinnie, N., Swart, J., 2012. Committed to whom? Professional knowledge worker commitment in cross-boundary organisations. Human Resource Management Journal, 22, 21-38.

Kornhauser, A., 1965. Mental Health of the Industrial Worker: A Detroit Study. New York: Wiley.

Krauss, S. I., Frese, M., Friedrich, C., Unger, J. M., 2005. Entrepreneurial orientation: A psychological model of success among southern African small business owners, European Journal of Work and Organizational Psychology, 14, 315-344.

Kreft, I. G. G., de Leeuw, J., 1998. Introducing multilevel modeling. Thousand Oaks, CA: Sage.

Kreiner, G. E., Ashforth, B. E., Sluss, D. M., 2006. Identity dynamics in occupational dirty work: Integrating social identity and system justification perspectives. Organization Science, 17, 619636.

Kristof-Brown, A. L., Zimmerman, R. D., Johnson, E. C., 2005. Consequences of individual's fit at work: A meta-analysis of person-job, person-organization, person-group, and person-supervisor fit. Personnel Psychology, 58, 281-342.

Lai, X., Li, F., Leung, K., 2013. A Monte Carlo study of the effects of common method variance on significance testing and parameter bias in Hierarchical Linear Modeling. Organizational Research Methods, 16, 243-269.

Lam, A., 2007. Knowledge networks and careers: Academic scientists in industry-university links. Journal of Management Studies, 44, 993-1016.

Lam, A., 2011. What motivates academic scientists to engage in research commercialization: 'Gold', ‘ribbon' or 'puzzle'? Research Policy, 40, 1354-1368.

Lam, A., Lambermont-Ford, J.-P., 2010. Knowledge sharing in organisational contexts: A motivation-based perspective. Journal of Knowledge Management, 14, 51-66. 
Lang, J., Thomas, J. L., Bliese, P. D., Adler, A. B., 2007. Job demands and job performance: The mediating effect of psychological and physical strain and the moderating effect of role significance. Journal of Occupational Health Psychology, 12, 116-124.

Lavrakas, P., 2008. Encyclopedia of survey research methods (Vol. 1). Thousand Oaks, CA: Sage.

Liebeskind, J., Oliver, A., Zucker, L., Brewer, M., 1996. Social networks, learning, and flexibility: Sourcing scientific knowledge in new biotechnology firms. Organization Science, 7, 428-443.

Lindenberg, S., 2001. Intrinsic motivation in a new light. Kyklos, 54, 317-342.

Locke, E. A., Latham, G. P., 2002. Building a practically useful theory of goal setting and task motivation: A 35-year odyssey. American Psychologist, 57, 705-717.

Lumpkin, G. T., Dess, G. G., 1996. Clarifying the entrepreneurial orientation construct and linking it to performance. Academy of Management Review, 21, 135-172.

Mainemelis, C., 2010. Stealing fire: Creative deviance in the evolution of new ideas. Academy of Management Review, 35, 558-578.

Marinova, S. V., Peng, C., Lorinkova, N., Van Dyne, L., Chiaburu, D., 2015. Change-oriented behavior: A meta-analysis of individual and job design predictors. Journal of Vocational Behavior, 88, 104120.

Mathieu, J. E., Zajac, D. M., 1990. A review and meta-analysis of the antecedents, correlates and consequences of organizational commitment. Psychological Bulletin, 108, 171-194.

May, T., Korczynski, M., Frenkel, S. J., 2002. Organizational and occupational commitment: Knowledge workers in large corporations. Journal of Management Studies, 39, 775-801.

MacCallum, R. C., Browne, M. W., \& Sugawara, H. M., 1996. Power analysis and determination of sample size for covariance structure modeling. Psychological Methods, 1, 130-149.

Meyer, J. P., Stanley, D. J., Herscovitch, L., Topolnytsky, L., 2002. Affective, continuance, and normative commitment to the organization: A meta-analysis of antecedents, correlates, and consequences. Journal of Vocational Behavior, 61, 20-52. 
Miller, C. C., Cardinal, L. B., 1994. Strategic planning and firm performance: A synthesis of more than two decades of research. Academy of Management Journal, 37, 1649-1665.

Miller, D. J., Fern, M. J., Cardinal, L. B., 2007. The use of knowledge for technological innovation within diversified firms. Academy of Management Journal, 50, 308-326.

Morrow, P. C., Wirth, R. E., 1989. Work commitment among salaried professionals. Journal of Vocational Behavior, 34, 40-56.

Motowidlo, S. J., Borman, W. C., Schmit, M. J., 1997. A theory of individual differences in task and contextual performance. Human Performance, 10, 71-83.

Noble, C. H., Mokwa, M. P., 1999. Implementing marketing strategies: Developing and testing a managerial theory. Journal of Marketing, 63, 57-73.

Panaccio, A., Vandenberghe, C., 2011. The relationships of role significance and organization-based selfesteem to commitment to supervisors and organizations and turnover intentions. Journal of Applied Social Psychology, 41, 1455-1485.

Parks, J. M., Kidder, D. L., Gallagher, D. G., 1998. Fitting square pegs into round holes: Mapping the domain of contingent work arrangements onto the psychological contract. Journal of Organizational Behavior, 19, 697-730.

Parks, J. M., Ma, L., Gallagher, D. G., 2010. Elasticity in the 'rules' of the game: Exploring organizational expedience. Human Relations, 63, 701-730.

Pereira, G. M., Osburn, H. G., 2007. Effects of participation in decision making on performance and employee attitudes: A quality circles meta-analysis. Journal of Business and Psychology, 22, 145153

Perry, S. J., Currall, S. C., Stuart, T. E., 2007. The pipeline from university laboratory to new commercial product: An organizational framework regarding technology commercialization in multidisciplinary research centers, in: Davila, T., Epstein, M. J., Shelton, R. (Eds.), The Creative Enterprise. Praeger Publishers: Westport, CT., pp. 85-106. 
Podsakoff, P. M., MacKenzie, S. B., Podsakoff, N. P., 2012. Sources of method bias in social science research and recommendations on how to control it. Annual Review of Psychology, 65, 539-569.

Porter, L. W., Steers, R. M., Mowday, R. T., Boulian, P. V., 1974. Organizational commitment, job satisfaction, and turnover among psychiatric technicians. Journal of Applied Psychology, 59, 603609.

Preacher, K., 2015. Multilevel modeling: A second course [in-person workshop coordinated by Statistical Horizons].

Rizzo, J. R., House, R. J., Lirtzman, S. I., 1970. Role conflict and ambiguity in complex organizations. Administrative Science Quarterly, 15, 150-163.

Roach, M., Sauermann, H, 2010. A taste for science? PhD scientists' academic orientation and selfselection into research careers in industry. Research Policy, 39, 422-434.

Robinson, P. B., Stimpson, D. V., Huefner, J. C., Hunter, H. K., 1991. An attitude approach to the prediction of entrepreneurship. Entrepreneurship Theory and Practice, 15, 13-31.

Saks, A. M., Uggerslev, K. L., Fassina, N. E., 2007. Socialization tactics and newcomer adjustment: A meta-analytic review and test of a model. Journal of Vocational Behavior, 70, 413-446.

Sauermann, H., Cohen, W. M., 2010. What makes them tick? Employee motives and firm innovation. Management Science, 56, 2134-2153.

Schein, E. H., 1971. Occupational socialization in the professions: The case of role innovation. Journal of Psychiatric Research, 8, 521-530.

Smilor, R. W., Dietrich, G. B., Gibson, D. V., 1993. The entrepreneurial university: The role of higher education in the United States in technology commercialization and economic development. International Social Science Journal, 45, 1-11.

Solinger, O. N., van Olffen, W., Roe, R. A., Hofmans, J., 2013. On becoming (un)committed: A taxonomy and test of newcomer onboarding scenarios. Organization Science, 24, 1640-1661.

Stone, E. F., \& Hollenbeck, J. R, 1989. Clarifying some controversial issues surrounding statistical procedures for detecting moderator variables: Empirical evidence and related matters. Journal of 
Applied Psychology, 74, 3-10.

Sturges, J., Conway, N., Guest, D., Liefooghe, A., 2005. Managing the career deal: The psychological contract as a framework for understanding career management, organizational commitment and work behavior. Journal of Organizational Behavior, 26, 821-838.

Tubre, T. C., Collins, J. M., 2000. Jackson and Schuler (1985) revisited: A meta-analysis of the relationships between role ambiguity, role conflict, and job performance. Journal of Management, 26, 155-169.

Tuma, N. B., Grimes, A. J., 1981. A comparison of models of role orientations of professionals in a research-oriented university. Administrative Science Quarterly, 26, 187-206.

Turnley, W. H., Feldman, D. C., 2000. Re-examining the effects of psychological contract violations: Unmet expectations and job dissatisfaction as mediators. Journal of Organizational Behavior, 21, $25-42$.

Wallace, J. E., 1993. Professional and organizational commitment: Compatible or incompatible? Journal of Vocational Behavior, 42, 333-349.

Wang, X., Armstrong, A., 2004. An empirical study of PM professionals' commitment to their profession and employing organizations. International Journal of Project Management, 22, 377-386.

Williams, L. J., Cote, J. A., Buckley, M. R., 1989. Lack of method variance in self-reported affect and perceptions at work: Reality or artifact. Journal of Applied Psychology, 74, 462-468. 


\section{Appendix A}

\section{Fit Statistics for Full Measurement Model}

Table A.1

Fit Statistics for Comparison Measurement Models

\begin{tabular}{llllll}
\hline Model & $\chi^{2}(\mathbf{d f})$ & CFI & TLI & RMSEA & SRMR \\
\hline Revised Organizational & $80.76(14)^{* *}$ & 0.96 & 0.94 & 0.14 & 0.03 \\
Commitment Measurement & & & & \\
Model & & & & \\
\hline Revised Professional & $34.84(9)^{* *}$ & 0.96 & 0.93 & 0.11 & 0.03 \\
Commitment Measurement & & & & \\
Model & & & & & \\
\hline Full Measurement Model & $424.06(220)^{* *}$ & 0.93 & 0.92 & 0.06 & 0.06 \\
\hline
\end{tabular}

Note. ${ }^{* *} p<.01$.

Table A.2

Aggregate Standardized Factor Loadings for Full Measurement Model

\begin{tabular}{lllll}
\hline Construct & Average & Minimum & Maximum & \# Items \\
\hline Organizational Commitment & .84 & .78 & .89 & 7 \\
Professional Commitment & .73 & .68 & .76 & 6 \\
Role significance & .86 & .84 & .93 & 2 \\
Innovation Orientation & .54 & .34 & .71 & 5 \\
\hline
\end{tabular}

Table A.3

Individual Standardized Factor Loadings for Full Measurement Model

\begin{tabular}{llc}
\hline Construct & Item & Standardized \\
& & Factor Loading \\
\hline $\begin{array}{l}\text { Organizational } \\
\text { Commitment }\end{array}$ & 2. I talk up this ERC to my friends as a great organization to be & .81 \\
& associated with.
\end{tabular}


4. I find that my values and the ERC's are very similar.

6. This ERC really inspires the very best in me in the way of job performance.

7. I am extremely glad that I chose this ERC to work with.

9. For me, this ERC is the best of all possible organizations with which to

work.

\begin{tabular}{|c|c|c|}
\hline \multirow{8}{*}{$\begin{array}{l}\text { Professional } \\
\text { Commitment }\end{array}$} & 1. Building my professional reputation in my field. & .76 \\
\hline & 2. Belong to the professional community of others in my field. & .72 \\
\hline & 3. Improve my knowledge in my field. & .73 \\
\hline & 5. Keep in contact with others in my profession. & .73 \\
\hline & 6. Earn respect in the eyes of colleagues in my field outside my & .74 \\
\hline & employing organization. & \\
\hline & 7. Have an adequate level of salary relative to colleagues in my field & .68 \\
\hline & outside my employing organization. & \\
\hline \multirow[t]{2}{*}{ Role Significance } & 1. I am aware of my thrust(s)' role in achieving the ERC's strategic plan. & .83 \\
\hline & 2. I am aware of my role in achieving the ERC's strategic plan. & .84 \\
\hline \multirow{6}{*}{$\begin{array}{l}\text { Innovation } \\
\text { Orientation }\end{array}$} & 1. Most of my time is spent working on several ideas at the same time. & .46 \\
\hline & 2. I usually delegate routine tasks after only a short period of time. & .34 \\
\hline & 3. I usually take control in unstructured situations. & .49 \\
\hline & 4. I often approach tasks in unique ways. & .68 \\
\hline & 5. I usually seek out colleagues who are excited about exploring new & .71 \\
\hline & ways of doing things. & \\
\hline
\end{tabular}

